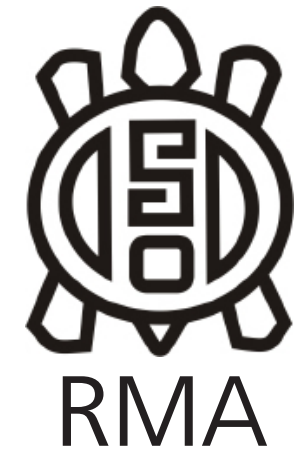

Arqueología

\section{Análisis faunístico del sitio Quequén Salado 1. Subsistencia de cazadores recolectores del Holoceno tardío en el litoral marítimo pampeano}

Faunal analysis of the site Quequén Salado. Subsistence of huntergatherers of the late Holocene on the Pampas maritime coast

Diego Catriel Leon*

* CONICET, Instituto de Estudios Sociales para el Desarrollo Social, Facultad de Humanidades, Cs. Sociales y de la Salud, Universidad Nacional de Santiago del Estero, Argentina. E-mail: catriel_leon@hotmail.com

\begin{abstract}
Resumen
Quequén Salado 1 es un sitio localizado en la margen izquierda del río homónimo (partido de Tres Arroyos, provincia de Buenos Aires, Argentina) y a pocos kilómetros de la línea de costa actual. Los primeros análisis permitieron definir una sucesión de ocupaciones correspondientes al Holoceno tardio final por parte de cazadores-recolectores que, en sus ciclos anuales de movilidad, se establecieron en las llanuras adyacentes a la cadena de médanos litorales del área Interrserrana. En este trabajo se presentan los análisis zooarqueológicos y tafonómicos que permiten abordar tanto los procesos de formación del sitio como la subsistencia. Los resultados indican procesos intensos de mezcla de materiales así como de destrucción de restos y una explotación faunística similar a la del interior pampeano. Esta información es discutida en el marco de los modelos de ocupación del litoral marítimo y de subsistencia para el Holoceno tardío.
\end{abstract}

Palabras clave: Región pampeana; Litoral marítimo; Holoceno tardío; Cazadores-recolectores; Subsistencia.

\begin{abstract}
Quequén Salado 1 site is located on the left bank of the homonymous river (Tres Arroyos, province of Buenos Aires, Argentina) and distant a few kilometers from the current coastline. The first analyzes allowed to define a succession of occupations corresponding to the final late Holocene by hunter-gatherers who, in their annual mobility cycles, were established in the plains adjacent to the coastal dunes chain of the Interrserrana area. This work presents the zooarcheological and taphonomic analyzes that allow addressing both the formation processes of the site and the subsistence. The results indicate intense processes of mixing materials as well as destruction of remains and a wildlife exploitation similar to that of the Pampas interior. This information is discussed in the framework of the occupation models of the sea coast and subsistence for the late Holocene.
\end{abstract}

Keywords: Pampean región; Maritime litoral; Late Holocene; Hunter-gatherers; Subsistence.

En determinadas zonas costeras del litoral atlántico sudamericano existen numerosas evidencias arqueológicas sobre la utilización de los recursos marítimos e incluso una adaptación humana específica a este medio acuático. La fauna marina fue utilizada con frecuencia por las sociedades indígenas que ocuparon distintas zonas, desde el norte de Brasil hasta el extremo sur del continente (Patagonia y Tierra del Fuego) (Bonomo 2011; Inda et al. 2006; Lima 1999-2000; Orquera y Gómez Otero 2007). En este contexto suprarregional, la escasez de fauna marina registrada en los sitios arqueológicos del litoral marítimo del área Interserrana bonaerense convierte a este sector en un caso singular para estudios arqueofaunísticos.
Para el caso del litoral del área Interserrana, Bonomo (2004) planteó un modelo para explicar la utilización diferencial del ambiente costero actual desde mediados del Holoceno (ca. 6500 años AP) por los mismos grupos cazadores-recolectores de las llanuras interiores. Sin embargo, la escasez de contextos estratigráficos en el litoral pampeano y los problemas de preservación de los restos faunísticos en la cadena de médanos limitaron las inferencias sobre la subsistencia de las poblaciones allí asentadas (Bonomo 2004; Politis 1984). Recientemente, Bonomo et al. (2013) y Leon (2014a) propusieron, a partir de distintas líneas de evidencia, que la subsistencia de los cazadores -recolectores experimentó una marcada 
continentalización hacia el Holoceno tardío.

Por otra parte, se han planteado distintos modelos de subsistencia para los cazadores-recolectores que ocuparon el sudeste de la región pampeana desde la transición Pleistoceno/Holoceno hasta finales del Holoceno tardío (Álvarez 2014; Gutiérrezy Martínez 2008; Martínez y Gutiérrez 2004; Miotti y Salemme1999; Politis y Salemme 1990; Quintana y Mazzanti 2001, entre otros). Específicamente, para el Holoceno tardío (3500-500 años AP) se sugirió a escala regional, el desarrollo de economías areales de diversificación e intensificación (Martínez y Gutiérrez 2004). Pero, para el área Interserrana habría existido una continuidad desde mediados del Holoceno medio, y por tanto una economía especializada en la caza del guanaco (Álvarez 2014; Frontini 2013; Leon 2014a; Martínez y Gutiérrez 2004; Massigoge 2007; Massigoge et al. 2018; Messineo 2011). Martínez y Gutiérrez (2004:87) destacan que el proceso de intensificación estaría relacionado con un mayor consumo de vegetales. Sin embargo, Salemme y Madrid (2007) indican una mayor diversidad faunística en la dieta indígena para este momento. Otros autores acotan temporalmente lo que podría ser el inicio de la diversificación faunística hacia el $1000 \mathrm{AP}$, no sin destacar el rol principal del guanaco en la subsistencia hasta momentos previos al contacto hispano-indígena (Álvarez y Salemme 2015; Bonomo et al. 2008; Massigoge et al. 2018).

En este trabajo se presentan nuevos análisis del material faunístico del sitio Quequén Salado 1 y se retoma la información generada por diferentes investigadores (Bonomo 2004; Gómez et al. 2005; Madrid et al. 2002; March et al. 2007; Steffan et al. 2010). El objetivo de este artículo es discutir esa nueva información y ponerla en relación con el modo de subsistencia propuesto por Martínez y Gutiérrez (2004) para el Holoceno tardío y con el modelo de ocupación diferencial del litoral marítimo del área Interserrana (Bonomo 2004).

\section{Sitio arqueológico Quequén Salado 1}

Entre 1999 y 2002, en el marco de un proyecto de cooperación internacional SETCIP-ECOSsud (A98H02) entre Argentina (INCUAPA, FACSO, UNCPBA) y Francia (Univ. Rennes 1), se llevaron a cabo investigaciones arqueológicas en toda la cuenca del río Quequén Salado. Este proyecto fue dirigido por los Dres. Gustavo Politis, Jean Laurent Monnier, Ramiro March y la Lic. Patricia Madrid. En el transcurso de esas investigaciones se localizó y excavó el sitio arqueológico Quequén Salado 1.

Quequén Salado 1 (en adelante QS1) se ubica a los $38^{\circ}$ $49^{\prime} 44,2^{\prime \prime} \mathrm{S}$ y $60^{\circ} 32^{\prime} 11,8^{\prime \prime} \mathrm{O}$ sobre la margen izquierda del río homónimo y a $11 \mathrm{~km}$ de distancia de la línea de costa actual del océano Atlántico (Partido de Tres Arroyos, Provincia de Buenos Aires; Figura 1). Los trabajos de campo se realizaron en cuatro campañas sucesivas, entre

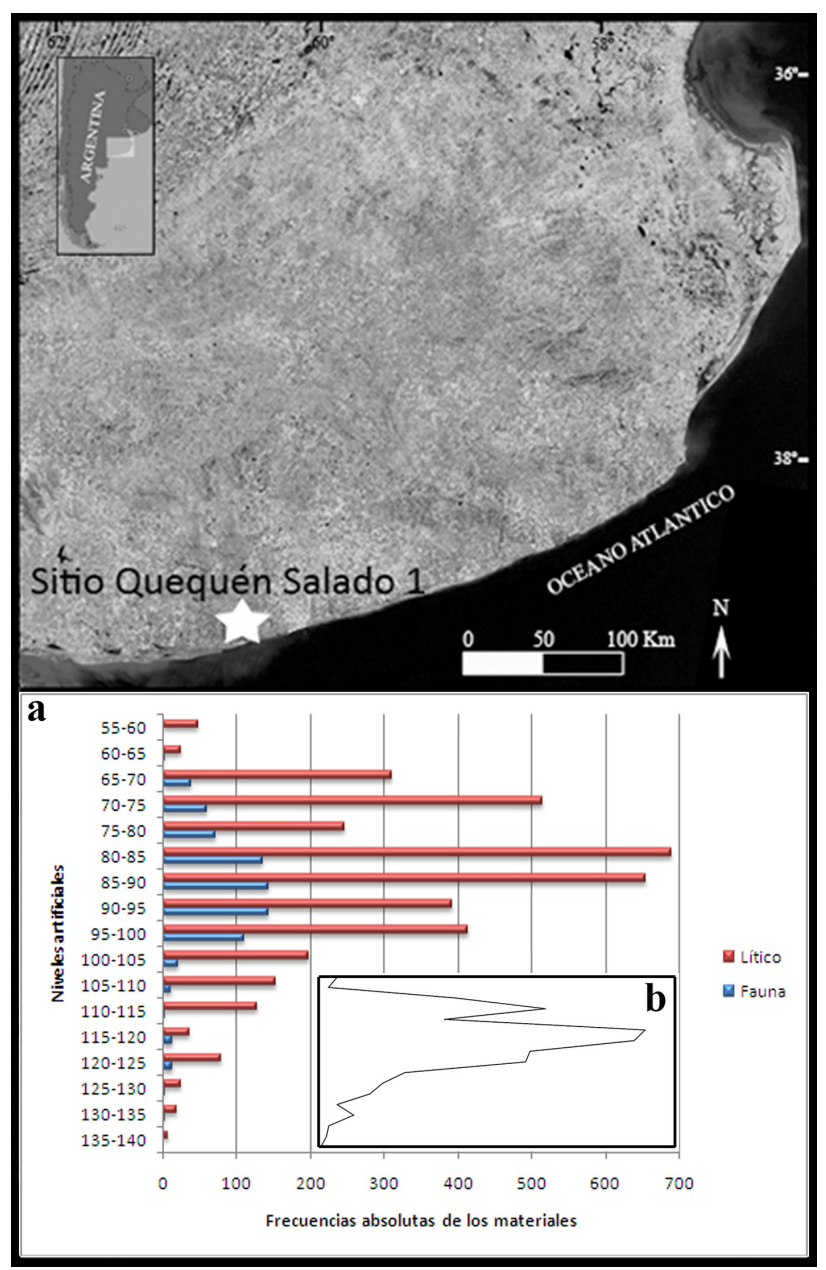

Figura 1. Localización (arriba) y distribución vertical de los materiales arqueológicos de QS1 (abajo): (a) total de artefactos líticos y los especímenes faunísticos de planta; (b) suma del total de artefactos líticos y los especímenes faunísticos de planta.

Figure 1. Location (top) and vertical distribution of QS1 archaeological materials (bottom): (a) total lithic artifacts and plant faunal specimens; (b) sum of total lithic artifacts and plant faunal specimens.

el 2000 y 2002, totalizando una superficie excavada de $25 \mathrm{~m}^{2}$. Los materiales arqueológicos se distribuían entre los 50 y $140 \mathrm{~cm}$ de profundidad desde el nivel 0, con una mayor concentración de hallazgos entre los 65 y $100 \mathrm{~cm}$ (Figura 1).

De acuerdo con observaciones de campo y análisis texturales, en QS1 se identificaron dos unidades estratigráficas mayores y seis estratos. La unidad inferior referible al Miembro Río Salado de la Formación Luján (Estratos VI y V), con su techo a los $95 \mathrm{~cm}$ de profundidad. La unidad superior vinculable con la Formación La Postrera (Estratos IV, III; II y I) y se desarrolla entre los $95 \mathrm{~cm}$ y el nivel 0 del sitio (Figura 2).

El estrato VI es de origen fluvio-lacustre, en tanto que 
el $\mathrm{V}$, de materiales sedimentarios transicionales, fue interpretado como un depósito de pantano. Hacia arriba, mediante un límite claro y ondulado se observa un paleosuelo cumúlico (estratos IV, III y II), con una secuencia de horizontes poco evolucionados (2C, 2A2, 2A1). Es sobre todo en el horizonte $C$, material parental de origen eólico, donde se concentró la mayor densidad de restos arqueológicos (Figura 2). Finaliza la secuencia estratigráfica un depósito que corresponde al suelo actual con un horizonte A1 incipiente (estrato I) (Steffan et al. 2010:220).

Para la reconstrucción paleoambiental a escala local y areal se consideraron estudios geoarqueológicos, malacológicos, faunísticos (micro y mesofauna) y de polen (Grill et al. 2010; Steffan et al. 2010). En el sector inferior del sitio (Estratos VI y V) se identificó un cuerpo de agua que se fue desecando hasta generar un ambiente pantanoso en condiciones areales tendientes a una mayor aridización. La acumulación eólica (Estrato IV), que coincide con la mayor concentración de materiales arqueológicos, se dio en un entorno localmente húmedo y con vegetación sammofila típica de ambientes de médanos (inter-duna y/o dunas fijas). Luego devino en la formación de un suelo de tipo cumúlico (Estratos III y II), que para Steffan et al. (2010) fue en condiciones de mayor humedad y para Grill et al. (2010) indicarían un desmejoramiento climático hacia los 360 años AP. La secuencia finaliza con una nueva acumulación eólica y el desarrollo del suelo actual (Estrato I). Una conclusión a la que arribaron Grill et al. (2010) y Steffan et al. (2010) es que en QS1 las condiciones fueron localmente húmedas en un contexto general árido/semi-árido.

En QS1 se recuperaron 4559 artefactos líticos, 15 tiestos cerámicos, 204 fragmentos de pigmentos minerales, espículas de carbón y unos 10895 restos faunísticos. Bonomo (2004) analizó 943 artefactos líticos; determinando que el conjunto está conformado tanto por rodados costeros (33\%) como por rocas del interior
$(59,5 \%)$ y que esta muestra está integrada por desechos de talla (93\%), instrumentos $(5,8 \%)$ y núcleos $(1,2 \%)$. Entre los instrumentos, este autor, destacó la manufactura local de puntas de proyectil (principalmente en rodados costeros) y bolas de boleadoras (en tosca). Asimismo, se mencionó que mientras las puntas de proyectil se elaboraron principalmente en rodados costeros, los raspadores y las raederas fueron producidas sobre todo en rocas del interior.

Por otro lado, los restos faunísticos han sido estudiados con distinta profundidad y con diferentes objetivos. Así, G. Gómez efectuó el análisis tafonómico de los restos de Micro y Meso Mammalia y sus implicancias paleoambientales (Gómez et al. 2005; Steffan et al. 2010). D. Joly analizó los restos termoalterados (Grill et al. 2010) y C. Rodríguez Loredo llevó a cabo un estudio zooarquelógico preliminar de los materiales procedentes de las plantas de excavación (Grill et al. 2010; March et al. 2007).

Con respecto a la cronología, los fechados sobre cuatro especímenes de Lama guanicoe procedentes de diferentes profundidades arrojaron edades que ubican las ocupaciones de QS1 hacia el Holoceno tardío final (Madrid et al. 2002: Tabla 4). Aunque las distribuciones verticales de los especímenes faunísticos provenientes de la planta de excavación y de los artefactos líticos no permiten discriminar claramente varias ocupaciones (Figura 1a), esos fechados permitirían establecer al menos dos eventos ocupacionales. El más temprano habría sucedido entre los 960 y 790 años AP en momentos pre-hispánicos y el más tardío se habría llevado a cabo en torno a los 360 años $A P$, en momentos cercanos de la conquista o bien ya en el período colonial. Pero como destacara Bonomo (2004) no se halló ningún elemento post-hispánico (por ejemplo, vidrio, loza) (Madrid et al. 2002). Madrid et al. (2002) y March et al. (2007) mencionaron que este último fechado debería ser contrastado con más dataciones y la ampliación de las excavaciones. En tanto que, Politis y Pedrotta (2006)

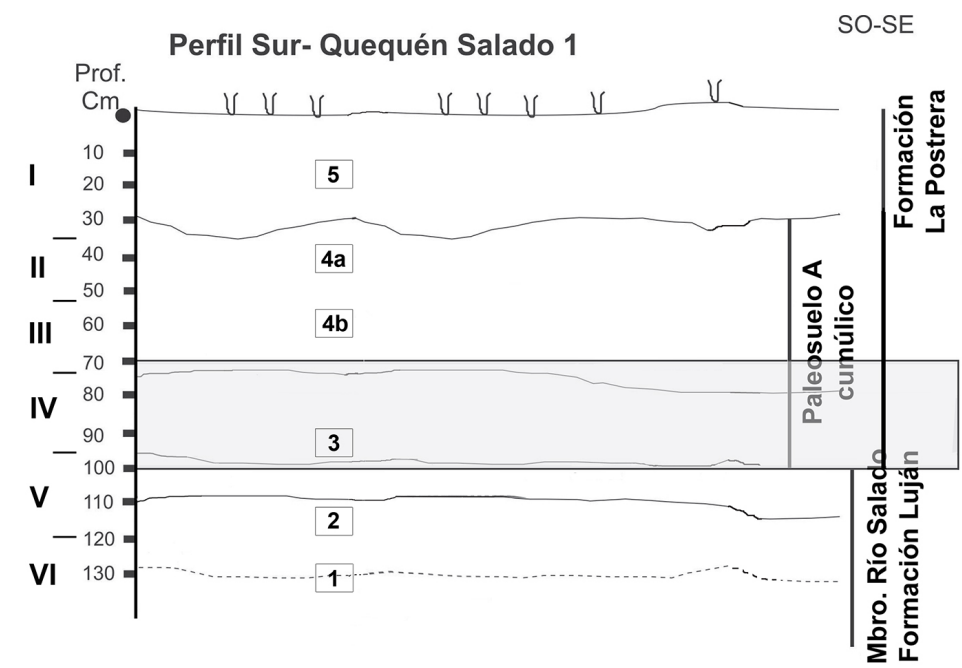

Mayor densidad de elementos arqueológicos
Figura 2. Estratigrafía del sitio. Perfil Sur. Imagen tomada de Steffan et al. (2010:Figura 5) y modificada. En los recuadros las seis muestras analizadas y sobre el margen izquiero en numeros romanos los Estratos determinados. Escala $1=10 \mathrm{~cm}$.

Figure 2. Stratigraphy of the site. South profile. Image taken from Steffan et al. (2010: Figure 5) and modified. In the boxes the six samples analyzed and on the left margin in Roman numbers the determined strata. Scale $1=10 \mathrm{~cm}$. 
consideraron que la edad obtenida sobre un resto de $L$. guanicoe se trataría de un outlier o que correspondería a la muerte real de un individuo perteneciente a poblaciones relictuales (Politis y Pedrotta 2006:304).

\section{Materiales y Métodos}

La muestra arqueofaunística estudiada en este trabajo ( $\mathrm{n}=$ 889) corresponde al material procedente de las plantas de excavación de 21 cuadrículas de las 25 excavadas en QS1. Además, en la sección determinación y cuantificación, sobre todo taxonómica, se consideró tanto la muestra anterior ( $n=889)$ como la analizada por el Dr. G Gómez $\left(n=3340^{1}\right)$, esta última proviene del material faunístico recuperado en el cernido del sedimento de las mismas 21 cuadrículas. Las variables tafonómicas fueron relevadas en una sub-muestra de 721 especímenes, ya que se excluyeron los restos indeterminados menores a $2 \mathrm{~cm}$, los elementos de micro-vertebrados, las placas dérmicas, los dientes y el fragmento de Mollusca. En tanto que, al considerar las variables del procesamiento antrópico, la sub-muestra estuvo conformada también por 721 especímenes (del N=4229 -889 de planta y 3340 de cernidor-), este número se obtuvo tanto de los materiales analizados por el autor de este artículo sumados a la información provista por los trabajos de Grill et al. (2010) y March et al. (2019) sobre los taxa con restos termoalterados (véase más adelante).

La identificación de los materiales faunísticos a nivel anatómico y taxonómico se efectúo a través de la comparación con colecciones de referencia pertenecientes a distintas divisiones del Museo de La Plata (Facultad de Ciencias Naturales y Museo de la Universidad Nacional de La Plata (UNLP). Además, se consultó la colección de Lama guanicoe del INCUAPA (CONICET-UNICEN), formada por C. Kaufmann. La edad de los individuos de guanaco se consignó a partir del estado de fusión de los huesos largos y se asignó a un estadío ontogenético (sensu Kaufmann 2009). Para la determinación taxonómica y anatómica de vertebrados de tamaño similar a Lama guanicoe, Ozotoceros bezoarticus y Rheidae se aplicó a una muestra de 54 huesos largos de Mammalia grande e Indeterminados, la propuesta metodológica desarrollada por Leon (2010, 2014b) a partir de los rasgos cualitativos internos de la cavidad medular y del espesor de las diáfisis. Se cuantificó la diversidad taxonómica utilizando las medidas NISP y NMI. En tanto que la abundancia anatómica se midió a través del NME, MAU y MAU\% (Binford 1978; Grayson 1984; Lyman 2008; Mengoni Goñalons 1999, entre otros).

Distintas variables tafonómicas fueron registradas para evaluar la historia del conjunto faunístico y los diferentes procesos que afectaron la integridad del sitio:

\footnotetext{
${ }^{1}$ A esta muestra de cernidor no se accedió directamente, sino a través de las planillas Excel que fueron cedidas gentilmente por Gómez.
}

meteorización, abrasión geológica², depositaciones químicas, acción de carnívoros y roedores, marcas de raíces, disolución y degradación química ${ }^{3}$ y fracturas (Behrensmeyer 1978; Binford 1981; Shipman 1981; Johnson 1985; Lyman 1994; Fisher 1995; Gutiérrez 2004, entre otros). Debido a la gran cantidad de restos de Ctenomys sp. (Steffan et al. 2010), se evaluó la distribución vertical por tamaño de los especímenes de los vertebrados grandes ${ }^{4}(n=228)$ y una muestra de los artefactos líticos ( $n=905)$ siguiendo los criterios propuestos por Bocek (1986) y Durán (1991) para pocket gopher y Ctenomys sp.,

Como proponen distintos investigadores (Binford 1981; Borrero 1989; Bonomo 2004, Álvarez y Salemme 2015; entre otros) se consideró la supervivencia diferencial mediada por la densidad mineral ósea a partir de las distintas proporciones (MAU\%) de las epífisis proximal y distal (con bajas y altas densidades, respectivamente) de la tibia y el húmero de guanaco (Borrero 1989). Para complementar lo anterior se utilizó la proporción de carpianos-tarsianos enteros de este camélido para examinar la intensidad de la fragmentación postdepositacional (Marean 1991).

Por otra parte, se describieron las modificaciones óseas vinculadas con el procesamiento antrópico: huellas de corte (Binford 1981; Nilssen 2000), fracturas (Johnson 1985) y alteraciones térmicas (Buikstra y Swegle 1989; Mengoni Goñalons 1999). La abundancia estandarizada de partes esqueletarias (MAU\%) de $L$. guanicoe se comparó, mediante el test rho de Spearman, con los Índices Utilidad de Carne y de Médula Ósea de guanaco (Borrero 1990; Mengoni Goñalons 1999) y, además, con el Índice de Secado de llama (De Nigris y Mengoni Goñalons 2005).

\footnotetext{
${ }^{2}$ Si bien Gutiérrez y Kaufmann (2007) organizaron en cuatro estadios de abrasión las modificaciones que generan los ambientes fluviales del área Intserserrana de la región pampeana, en este trabajo se utilizan estas categoría para evaluar la intensidad de este proceso: Estadio 1, los especímenes presentan brillo y textura suave; Estadio 2, los restos poseen bordes romos y; Estadio 3, refiere a la remoción del tejido cortical más externo y puede exponer el tejido trabecular en aquellos elementos que lo contengan. El Estadio 2-3 es para los especímenes que corresponden a fragmentos diafisiarios en los cuales es complejo distinguir entre el estadio 2 y 3 , ya que no poseen tejido trabecular. Además, en este trabajo se agrega el Estadio 0, que refiere a la ausencia de cualquiera de las características mencionadas.

3 En este trabajo se siguen los criterios macroscópicos propuestos por Gutiérrez (2004). Para el caso de la degradación química esta autora la describe como "la ausencia de la capa más externa de la superficie cortical, suave e irregular, la cual es reemplazada por una superficie que presenta una textura rugosa y áspera al tacto" (Gutiérrez 2004:407). En tanto que la disolución química u hoyos de disolución química es la presencia de hoyos y esculpidos en la superficie cortical del hueso. Gutiérrez $(1998,2004)$ propuso seis estadios con el propósito de medir la intensidad de este fenómeno que van del Estadio 1 (ausencia del efecto) al Estadio 6 (efectos severos que modifican la forma y tamaño original del hueso) (Gutiérrez 2004:51 y Figura III.2).

4 Incluye a Mammalia grande, L. guanicoe, O. bezoarticus y Rheidae.
} 
De manera complementaria, se utilizaron distintas herramientas teórico-metodológicas para interpretar el transporte, procesamiento de presas y composición taxonómica del conjunto faunístico. Se calculó la Utilidad Promedio (UP) (Nagaoka 2006, y bibliografía allí citada) para evaluar si se efectúo el transporte diferencial de guanaco. La UP de un guanaco entero es de 20,76 y considerando sólo los elementos de alta supervivencia ${ }^{5}$ es de 20,35. Además, para este camélido se usaron los Índices CABEZA/MIEMBROS y tNME/NMI estandarizado para evaluar los niveles de desorganización de una carcasa (Muñoz 2004, 2006, Stiner 1991). En el caso del Índice CABEZA/MIEMBROS el valor de referencia es de 0,3 para una carcasa completa al dividir los elementos de la cabeza (NME=3) por los de los miembros anterior $(\mathrm{NME}=6)$ y posterior $(\mathrm{NME}=4)^{6}$. En el caso de la Completitud Anatómica (tNME/NMI estandarizado) para L. guanicoe se calculó dividiendo la suma de los elementos de seis regiones anatómicas ${ }^{7}$ por el $\mathrm{NMI}$ estandarizado ${ }^{8}$, que para un guanaco es de 84 .

A su vez, y relacionado con el procesamiento y consumo de L. guanicoe, se emplearon el NISP/NME y la Completitud\% para medir la intensidad y extensión, respectivamente, de la fragmentación (Nagaoka 2006; Wolverton 2002). Para interpretar los resultados se tuvo en cuenta el trabajo de Wolverton (2002). Por último, la composición taxonómica del conjunto faunístico fue medida a través del Índice de Artiodáctilo (IA). El IA fue generado para medir la tasa de encuentro con animales altamente rankeados (Broughton 1994; Munro 2009; Ugan 2005; Rawlings2006, entre muchos otros) y se estimó dividiendo el NISP de Lama guanicoe por la suma de este último con el NISP de los mesomamíferos, Meso Rodentia ${ }^{9}$ y Dasypodidae (considerando los taxones con evidencias de utilización).

\section{Resultados}

Determinación y cuantificación de los restos faunísticos En la Tabla 1 se presentan las determinaciones taxonómicas alcanzadas, sus frecuencias absolutas y relativas y el número mínimo de individuos. Cabe aclarar que la

\footnotetext{
${ }^{5}$ Cráneo, Mandíbula, Húmero, RadioCúbito, Metacarpo, Fémur, Tibia y Metatarso.

${ }^{6}$ Se considera como parte de la cabeza a las dos hemi mandíbulas y al cráneo, al miembro anterior a las escápulas, húmeros y radiocúbitos y al miembro posterior a los fémures y tibias.

7 Regiones Anatómicas para un guanaco completo (NME esperados): Cabeza (Cráneo y Hemi Mandíbulas)=3; Columna (Vértebras y Hemi Pelvis)=29; Caja Torácica (Costillas y Esternebras)=30; Miembro Delantero (Escápulas, Húmeros y Radiocúbitos)=6; Miembro Trasero (Fémures y Tibias $)=4$ y Pies (Metacarpos, Metatarsos y $1^{\circ}$ Falanges $)=12$.

${ }^{8}$ Cabe aclarar que el NMI estandarizado se estima a partir de la región anatómica con el NME estandarizo más alto (NME observado/ esperado), y si este dio con una fracción se redondea hacia arriba (Muñoz 2006).

${ }^{9}$ En esta categoría se incluyó el resto faunístico que carecía de rasgos diagnósticos específico pero que por su tamaño y alguna morfología podría corresponder a roedores como la vizcacha y/o el coypo.
}

\begin{tabular}{|l|l|l|l|l|}
\hline \multicolumn{1}{|c|}{ TAXA } & \multicolumn{1}{|c|}{ NISP } & NISP\% & NMI & P \\
\hline Mammalia & 18 & 0,42 & - & - \\
\hline Mammalia grande & 195 & 4,5 & - & - \\
\hline Meso Mammalia & 66 & 1,6 & - & - \\
\hline Micro Mammalia & 166 & 3,8 & - & - \\
\hline Carnivora & 1 & 0,024 & - & - \\
\hline Galictis cuja & 1 & 0,024 & 1 & - \\
\hline Artiodactyla & 13 & 0,29 & - & - \\
\hline Lama guanicoe & 226 & 5,33 & 7 & $\mathrm{P}$ \\
\hline Ozotoceros bezoarticus & 16 & 0,38 & 2 & $\mathrm{P}$ \\
\hline Rodentia & 151 & 3,6 & 4 & $\mathrm{P}$ \\
\hline Ctenomys sp. & 2120 & 50,31 & 44 & - \\
\hline Akodon sp. & 2 & 0,046 & 1 & - \\
\hline Reithrodon auritus & 79 & 1,87 & 4 & - \\
\hline Lagostomus sp. & 19 & 0,45 & 2 & - \\
\hline Myocastor coypus & 3 & 0,069 & 1 & - \\
\hline Galea leucoblephara & 3 & 0,069 & 1 & - \\
\hline Dasypodidae & $325(274)$ & 7,7 & $1^{*}$ & $\mathrm{P}$ \\
\hline Chaetophractus villosus & $59(58)$ & 1,4 & 1 & - \\
\hline Zaedius pichiy & $(56)$ & 1,3 & 1 & - \\
\hline Dasypus hybridus & $(1)$ & 0,024 & 1 & - \\
\hline Ave & 1 & 0,024 & - & - \\
\hline Ave mediana & 1 & 0,024 & - & - \\
\hline Rheidae & 3 & 0,069 & 1 & $\mathrm{P}$ \\
\hline Mollusca & 1 & 0,024 & 1 & - \\
\hline Indeterminado > 2 cm & 277 & 6,55 & - & - \\
\hline Indeterminado < 2 cm & 426 & 10,1 & - & - \\
\hline Total & 4229 & 100 & - & - \\
\hline
\end{tabular}

Tabla 1. Composición taxonómica del sitio QS1. Referencias: $\mathrm{P}=$ procesamiento. Nota: entre paréntesis placas dérmicas. * NMI en base al promedio de placas móviles (véase Yepes 1928).

Table 1. Taxonomic composition of the QS1 site. References: $P$ = processing. Note: between parentheses dermal plates. ${ }^{*} \mathrm{NMI}$ based on average moving plates (see Yepes 1928).

abundancia anatómica de los taxa determinados por G. Gómez no fue estandarizada y se utilizó sólo el NISP como medida de cuantificación esqueletal.

Una alta proporción de especímenes pudieron ser determinados a algún nivel taxonómico (83,35\%). Como se observa en la Tabla 1 los diferentes taxa de Mammalia son los que dominan (83,21\%). De ellos, más del $60 \%$ de los especímenes corresponden a Ctenomys sp.. Le siguen en orden de importancia los Dasypodidae (12,53\%). Sin embargo, el $73,7 \%$ sólo pudo ser determinado a nivel de Familia mientras que los restantes pertenecen a Chaetophractus villosus (13,4\%), Zaedius pichiy $(12,7 \%)$ y Dasypus hybridus $(0,2 \%)$. Además de los Ctenomys sp. y los Dasypodidae se registró un número importante $(7,2 \%)$ de restos pertenecientes a Rodentia, así como a distintos géneros y especies de este Orden. Específicamente se destaca la presencia de Reithrodon auritus y de Lagostomus sp. con cantidades moderadas y de Akodon sp., Myocastor coypus y Galea leucoblephara con frecuencias bajas (Tabla 1). 
Dentro de los mamíferos grandes se reconoció al Orden Artiodactyla. Particularmente se registraron cantidades importantes de Lama guanicoe y con menor frecuencia Ozotoceros bezoarticus. Por otra parte, se determinó un espécimen de Carnivora y otro de Galictis cuja. Finalmente, para las Aves sólo se pudo establecer, a un nivel inferior al de Clase, la presencia de tres especímenes óseos de Rheidae.

La especie más importante registrada en QS1, tanto por su tamaño corporal como por la cantidad de especímenes, elementos anatómicos e individuos, es L. guanicoe (NISP=226; NME=137; NMI=7). A partir de la secuencia de fusión ósea (Kaufmann 2009) y por el tamaño de un ilion sin fusionar (menor al año), se estableció la presencia de un individuo neonato-cría, un juvenil/sub-adulto, un adulto/senil y uno de más de un año de edad al momento de su muerte (véase Leon 2014a). Con respecto a la abundancia anatómica de este taxón se observa que el esqueleto apendicular está mejor representado que el axial, siendo abundantes los húmeros, fémures, metapodios y tibias. Entre el esqueleto axial sólo tuvieron valores medios el cráneo y la hemi-pelvis (Tabla 2).

La co-variación entre el MAU\% y el Índice de Utilidad de Carne (IUC\%, Borrero 1990) fue baja, positiva y no significativa $(r S=0,1$ y $p=0,64)$. Al comparar estadísticamente con el Índice de Secado (IS\%, De Nigris y Mengoni Goñalons 2005) se obtuvo un valor alto, negativo y altamente significativo ( $r S=-0,8$ y $p=0,0003)$. En el caso del Índice de Médula (IM\%, Mengoni Goñalons 1999) los valores fueron altos, positivos y no significativos al considerar MAU\% de diáfisis de huesos largos y $1^{\text {a }}$ falange $(r S=0,75$ y $p=0,09)$.

El otro artiodáctilo representado fue el $O$. bezoarticus. Sin embargo, se registraron escasos especímenes, la mayoría pertenecientes al esqueleto apendicular (una escápula, tres húmeros, dos radios, un metacarpo, dos metapodios y dos falanges). Los especímenes de Mammalia grande y Artiodactyla pertenecen en su mayoría al esqueleto apendicular (NISP=123), en menor cantidad al esqueleto axial $(\mathrm{NISP}=27)$ (21 de ellos son vértebras, dos son costillas, dos hemi-pelvis y dos pertenecen a cráneo). Esta representación esqueletaria es semejante a la de $L$. guanicoe y $O$. bezoarticus

Con respecto a los Meso Mammalia, los Dasypodidae (NISP=325) se encuentran representados mayormente por placas dérmicas ( $n=274)$ y en menor medida por diferentes partes endoesqueléticas; 22 falanges, 18 dientes, una vértebra caudal, cinco vértebras indeterminadas, tres metapodios y un húmero. A nivel especifico se determinó al menos un individuo de Ch. villosus, uno de $Z$. pichiy y uno de $D$. hybridus. La única parte endoesqueletica

\begin{tabular}{|c|c|c|c|c|c|c|c|c|c|c|c|c|c|c|c|}
\hline \multirow{2}{*}{$\begin{array}{c}\text { Unidad } \\
\text { Anatómica }\end{array}$} & \multicolumn{4}{|c|}{ No fusionado } & \multicolumn{4}{|c|}{ Fusionado } & \multicolumn{4}{|c|}{ Fusión Indt } & \multirow{2}{*}{ NME } & \multirow{2}{*}{ MAU } & \multirow{2}{*}{ MAU $\%$} \\
\hline & I & D & Ind & Ax & I & D & Ind & $A x$ & I & D & Ind & $A x$ & & & \\
\hline Cráneo & - & - & - & - & - & - & - & - & - & - & - & 3 & 3 & 3 & 60 \\
\hline H-mandí. & - & - & - & - & - & - & - & - & 1 & 2 & - & - & 3 & 1,5 & 30 \\
\hline \begin{tabular}{|l|} 
Molares \\
\end{tabular} & - & - & - & - & - & - & - & - & - & - & 14 & - & 14 & 1,16 & 23,2 \\
\hline Pre-molar & - & - & - & - & - & - & - & - & 1 & - & - & - & 1 & 0,16 & 3,32 \\
\hline \begin{tabular}{|l|} 
Atlas \\
\end{tabular} & - & - & - & - & - & - & - & - & - & - & - & 1 & 1 & 1 & 20 \\
\hline Axis & - & - & - & - & - & - & - & 1 & - & - & - & - & 1 & 1 & 20 \\
\hline V. Cerv. & - & - & - & - & - & - & - & 1 & - & - & - & 2 & 3 & 0,6 & 12 \\
\hline V. Toráx. & - & - & - & - & - & - & - & 2 & - & - & - & 2 & 4 & 0,33 & 6,6 \\
\hline V. Lum. & - & - & - & 3 & - & - & - & 6 & - & - & - & - & 9 & 1,29 & 25,8 \\
\hline \begin{tabular}{|l|} 
Costillas \\
\end{tabular} & - & - & - & - & - & - & - & - & - & 1 & - & - & 1 & 0,042 & 0,84 \\
\hline Escápula & - & - & - & - & 1 & 4 & - & - & - & 1 & - & - & 6 & 3 & 60 \\
\hline Húm. D & - & - & - & - & - & 1 & - & - & 3 & 6 & - & - & 10 & 5 & 100 \\
\hline Húm. Dis & - & - & - & - & 1 & 3 & - & - & - & 1 & - & - & 5 & 2,5 & 50 \\
\hline R-Cub. Px & - & - & - & - & - & - & - & - & 1 & - & - & - & 1 & 0,5 & 10 \\
\hline R.-Cub. D & - & - & - & - & - & 1 & - & - & 1 & 1 & - & - & 3 & 1,5 & 30 \\
\hline R-Cub Dis & - & - & - & - & - & 1 & - & - & - & - & - & - & 1 & 0,5 & 10 \\
\hline Metaca. Px & - & - & - & - & 1 & - & - & - & - & - & - & - & 1 & 0,5 & 10 \\
\hline Unciformes & - & - & - & - & - & - & - & - & 2 & 4 & - & - & 6 & 3 & 60 \\
\hline Magnum & - & - & - & - & - & - & - & - & - & 1 & - & - & 1 & 0,5 & 10 \\
\hline Pisciforme & - & - & - & - & - & - & - & - & 1 & - & 1 & - & 2 & 1 & 20 \\
\hline H-Pelvis & 1 & 1 & - & - & & 1 & - & - & 1 & - & - & - & 4 & 2 & 40 \\
\hline Fémur Px & - & 1 & - & - & - & - & - & - & - & - & - & - & 1 & 0,5 & 10 \\
\hline Fémur D & 1 & - & - & - & - & - & - & - & 4 & 3 & 2 & - & 10 & 5 & 100 \\
\hline Rótula & - & - & - & - & - & - & - & - & - & 1 & 1 & - & 2 & 1 & 20 \\
\hline Tibia Px & - & - & - & - & 1 & - & - & - & - & - & - & - & 1 & 0,5 & 10 \\
\hline Tibia D & - & - & - & - & - & - & - & - & 1 & 4 & - & - & 5 & 2,5 & 50 \\
\hline Tibia Dis & - & - & - & - & 2 & 4 & - & - & - & 1 & - & - & 7 & 3,5 & 70 \\
\hline Metata. Px & - & - & - & - & 1 & 2 & - & - & - & - & - & - & 3 & 1,5 & 30 \\
\hline Metata. D & - & - & - & - & 1 & - & - & - & - & - & - & - & 1 & 0,5 & 10 \\
\hline Astrágalo & - & - & - & - & - & - & - & - & 3 & 1 & 1 & - & 5 & 2,5 & 50 \\
\hline Calcáneo & - & - & - & - & - & - & - & - & 3 & 2 & - & - & 5 & 2,5 & 50 \\
\hline \begin{tabular}{|l|} 
Cuboide \\
\end{tabular} & - & - & - & - & - & - & - & - & 2 & 1 & - & - & 3 & 1,5 & 30 \\
\hline Ectocun. & - & - & - & - & - & - & - & - & 2 & - & - & - & 2 & 1 & 20 \\
\hline \begin{tabular}{|l|} 
Fibular \\
\end{tabular} & - & - & - & - & - & - & - & - & 2 & 1 & - & - & 3 & 1,5 & 30 \\
\hline Metap. D & - & - & 1 & - & - & - & - & - & - & - & 8 & - & 9 & 2,25 & 45 \\
\hline Metap. Dis & - & - & 1 & - & - & - & 6 & - & - & - & 9 & - & 16 & 4 & 80 \\
\hline $1^{\text {a }}$ Falange & - & - & - & - & - & - & 6 & - & - & - & 5 & - & 11 & 1,375 & 27 \\
\hline $2^{\mathrm{a}}$ Falange & - & - & - & - & - & - & 2 & - & - & - & 1 & - & 3 & 0,375 & 7,5 \\
\hline $3^{\text {a }}$ Falange & - & - & - & - & - & - & - & - & - & - & 1 & - & 1 & 0,125 & 2,5 \\
\hline
\end{tabular}
reconocida fue un metacarpo completo de peludo (Ch. villosus). De Lagostomus sp. se distinguieron 13 incisivos, dos restos de esmalte de diente, dos maxilares, un calcáneo y un fémur. En tanto que de $M$. coypus sólo se registraron especímenes correspondientes a dientes incisivos. Para las categorías taxonómicas amplias de Meso Mammalia (NISP=66) y de Rodentia (NISP=151), dentro de esta última los especímenes de Meso Rodentia (NISP=91, 57 de ellos esmalte de dientes), se identificaron diversos elementos esqueletales.

En relación con los Micro Mammalia se destaca la abundancia de Ctenomys sp. (Tabla 1). El número mínimo de individuos se estableció a partir de los maxilares (Gómez et al. 2005). Otros micro roedores determinados fueron $R$. auritus, G. leucoblephara y Akodon sp. (Tabla 1). Los especímenes que permitieron su identificación

Tabla 2. Perfil de partes esqueletarias de $L$. guanicoe para QS1. Referencias: I=izquierdo; $D=$ derecho; Ind=indeterminado; $A x=a x i a l ; P x=$ proximal; $D=$ diáfisis; Dis=distal.

Table 2. Profile of skeletal parts of $L$. guanicoe for QS1. References: I = left; $D=$ right; Ind = indeterminate; $A x=$ axial; $P X=$ proximal; $D=$ diaphysis; Distal dis. 
correspondieron en su mayoría al cráneo y se registraron elementos como vértebras, escápulas, húmero, radio, ulna, pelvis, fémur, tibia y falanges en las categorías más amplias (Micro Mammalia y Micro Rodentia).

Con escasa frecuencia fueron determinados un canino de Carnivora y un $1^{\circ}$ molar de G. cuja. Dentro de la Aves se identificó a una Rheidae, cuyas partes esqueletarias correspondieron a dos tibiotarsos y a un fémur. Además, se identificó un fragmento de exoesqueleto de un Mollusca. Finalmente, al aplicar la propuesta metodológica de Leon $(2010,2014 b)$ se re-ajustaron las determinaciones de 54 especímenes. De esa manera, se asignó un fragmento diafisiario al fémur de un ave de tamaño similar a Rheidae. En tanto que otros seis especímenes corresponderían a mamífero, de tamaño similar a L. guanicoe: cuatro elementos al esqueleto apendicular superior, uno al esqueleto apendicular medio y/o inferior y uno al esqueleto apendicular.

\section{Análisis Tafonómico}

En la Tabla 3 se muestran los resultados del análisis de los efectos tafonómicos de los 721 especímenes.

Sólo en el 14,3\% ( $n=103)$ de la muestra se pudo determinar la presencia o ausencia de meteorización (véase en discusión). Si bien en esta muestra los estadios 1, 2 y 3 se distribuyen de manera equilibrada (totalizando el $89,3 \%)$, son estos dos últimos estadios $(75,62 \%$ de un $n=66$ ) los que dominan entre los 80 y $100 \mathrm{~cm}$ de profundidad. Por otra parte, el 9,7\% de los materiales presentaron abrasión geológica (en el estadio 1 y 2). Los especímenes con estadio 2 de abrasión se recuperaron en su totalidad por encima de los $80 \mathrm{~cm}$. Por otro lado, se destaca que debajo de los $100 \mathrm{~cm}$ de profundidad el 34\% de los especímenes presentaba algún grado de abrasión. Las depositaciones químicas (0,55\% Carbonatos de Calcio y 2,25\% Óxidos de Manganeso) y la actividad de carnívoros se registraron en escasas proporciones.

Por otro lado, si bien las marcas de roedores se reconocieron en el $8,74 \%$, de los especímenes de la muestra total, este porcentaje desciende a menos de la mitad (valores entre 2,2 a 3,5\%) por encima de los $75 \mathrm{~cm}$ de profundidad y aumenta a más del $11 \%$ por debajo de los $95 \mathrm{~cm}$. Ctenomys sp., además de ser probablemente el principal responsable de las marcas de roedor, podría haber ocasionado el desplazamiento vertical de los restos debido a su conducta fosorial. En la Figura $1 \mathrm{~b}$ se observa que al sumar los artefactos líticos y los especímenes faunísticos de planta se genera una distribución bimodal con dos picos, uno entre los $70-75 \mathrm{~cm}$ y el otro entre los 80-100 cm de profundidad.

Al descomponer esa bimodalidad por tipo de materiales (líticos $-n=905-$ y faunísticos $-n=228-$ ) y por tamaños se observa que entre los $70-75 \mathrm{~cm}$ de profundidad los litos de distintas dimensiones coinciden en cantidades
Tabla 3. Variables tafonómicas registradas en la muestra. Nota: *Porcentaje calculado sobre el total de la muestra.

Table 3. Taphonomic variables recorded in the simple. Note: * Percentage calculated on the total of the sample.

\begin{tabular}{|l|r|}
\hline & \multicolumn{1}{|c|}{ NISP\% } \\
\hline Meteorización & 9,6 \\
\hline Estadio 0 & 33 \\
\hline Estadio 1 & 34,9 \\
\hline Estadio 2 & 21,4 \\
\hline Estadio 3 & 1,1 \\
\hline Estadio 4 & 0 \\
\hline Estadio 5 & \\
\hline Abrasión Geológica & 90,3 \\
\hline Estadio 0 & 9,15 \\
\hline Estadio 1 & 0,55 \\
\hline Estadio 2 & 0 \\
\hline Estadio 2-3 & 0 \\
\hline Estadio 3 & 2,8 \\
\hline Depositación química & 1,1 \\
\hline Ac. Carnívoro & 8,74 \\
\hline Ac. Roedores & \\
\hline Disolución Química & 98,3 \\
\hline Estadio 1 & 0,97 \\
\hline Estadio 2 & 0,73 \\
\hline Estadio 3 & 0 \\
\hline Estadio 4 & 0 \\
\hline Estadio 5 & 0 \\
\hline Estadio 6 & 73,1 \\
\hline Degradación Química & 40,8 \\
\hline Marcas de Raíces & 96,7 \\
\hline Fracturas* & 10 \\
\hline Frescas & 33,8 \\
\hline Secas & 56,2 \\
\hline Indeterminadas & \\
\hline
\end{tabular}

porcentuales (Figura 3). En cambio, entre los $80-100 \mathrm{~cm}$ se registró una distribución vertical diferencial de estos artefactos, los más pequeños entre los $85-90 \mathrm{~cm}$ y los más grandes entre los $95-100 \mathrm{~cm}$ (Figura 3). Con respecto a la distribución de los restos faunísticos de vertebrados grandes $(n=228)$ se registra que esa bimodalidad está conformada por un pico superior $(70-75 \mathrm{~cm})$ de especímenes menores a los $2 \mathrm{~cm}$. En tanto que dentro de los 80-100 cm se dividen, a su vez, con un sub-pico entre los 80-90 cm de profundidad con la mayor frecuencia de especímenes de más de $2 \mathrm{~cm}$ y otro sub-pico con restos faunísticos menores a los $2 \mathrm{~cm}$ entre los $90-95 \mathrm{~cm}$.

Tres efectos tafonómicos que se tratan en grupo son los hoyos de disolución química (1,7\%), la degradación química $(73,1 \%)$ y las marcas de raíces $(40,8 \%)$. Estos efectos no sólo tuvieron altos porcentajes en la muestra (91,7\% de los especímenes estaban grabados) sino que también se registró muy extendido sobre la superficie de los especímenes (el 70\% de los especímenes tenían más del $66 \%$ de su superficie grabada). Es dable destacar que los porcentajes de especímenes con marcas de raíces (MR) y degradación química (DQ) aumentan y decrecen, respectivamente, desde los niveles superiores $(70-75 \mathrm{~cm}$; ca. $10 \% \mathrm{MR}$ y ca. $95 \% \mathrm{DQ})$ a los inferiores $(95-100 \mathrm{~cm}$; ca. $58 \% \mathrm{MR}$ y ca.45\% DQ).

La mayoría de los especímenes se hallaron fracturados $(96,7 \%)$; pero en un $56,2 \%$ no se pudo determinar el 
estado del hueso al momento de la fractura (fresco o seco) debido a que los materiales eran muy pequeños, pertenecían a epífisis de huesos largos o a fragmentos del esqueleto axial y/o, sobre todo, porque la superficie de fractura de los huesos se encontraba obliterada parcial o totalmente por la DQ y MR.

Para evaluar si existió una relación entre la densidad mineral y la preservación diferencial de las partes esqueletarias en el conjunto se consideraron las representaciones diferenciales de las epífisis de la tibia y del húmero de L. guanicoe. Como se observa en la Tabla 2 las epífisis más densas de estos dos elementos son las mejores representadas (tibia distal 70\% vs. 10\% su contraparte y el húmero distal es el único representado con el 50\%). Complementariamente, se registró un 51,8\% de tarsianos-carpianos completos para L. guanicoe.

\section{Procesamiento antrópico}

Los animales con evidencias de procesamiento antrópico fueron, por un lado, los Mammalia (NISP=718) integrados por L. guanicoe, O. bezoarticus, Dasypodidae y Rodentia $y$, por otro lado, Rheidae (NISP=3). Cabe aclarar que Dasypodidae y Rodentia fueron considerados también como explotados antrópicamente de acuerdo con la identificación de restos termoalterados (Grill et al. 2010; March et al. 2019).

Solo una huella de corte se registró en un fragmento

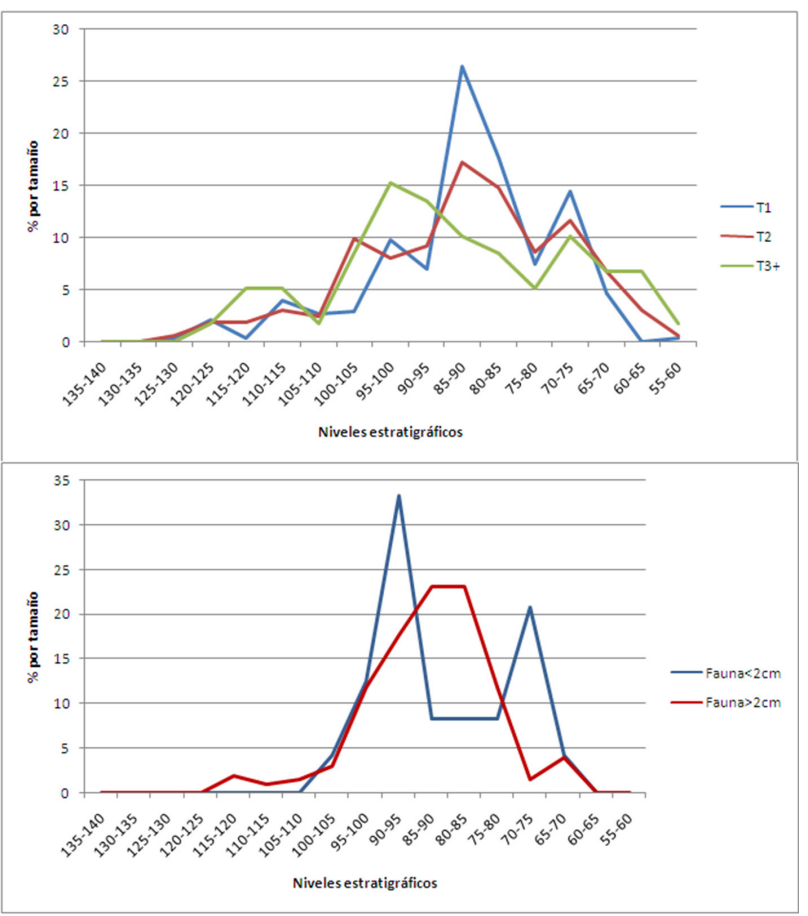

Figura 3. Distribución de los materiales arqueológicos por tamaño. Artefactos líticos tamaño 1, 2 y $\geq 3$ (T1, T2, T3+, arriba) (sensu Aschero 1975) y especímenes faunísticos (abajo)

Figure 3. Distribution of archaeological materials by size. Lithic artifacts size 1, 2 and $\geq 3(T 1, T 2, T 3+$, above) and faunal specimens (below) de diáfisis de fémur de L. guanicoe. De este taxón, fragmentos diafisiarios presentaron rasgos vinculados con las fracturas antrópicas (rasgos de fracturas en fresco, marcas de impacto y negativos de lascado): diez especímenes de húmero, siete de fémur, siete de metapodios, tres de radiocúbito, una $1^{\text {a }}$ falange y uno de tibia (solo dos $1^{\text {a }}$ falanges se registraron enteras). En relación con el otro artiodáctilo, 0 . bezoarticus, en un solo espécimen, un húmero, se reconoció fractura antrópica. Por otra parte, un fragmento de diáfisis de tibiatarso de Rheidae estaba fracturado antrópicamente.

Las modificaciones antrópicas se registraron también en especímenes pertenecientes a categorías taxonómicas amplias. En Mammalia grande (NISP=195) se observaron 23 fragmentos diafisiarios con fracturas antrópicas. De estos, y de acuerdo con la redeterminación efectuada, un fragmento diafisiario correspondería a fémur de Rheidae y tres al esqueleto apendicular superior de un Mammalia grande, similar a L. guanicoe. Además, en uno de estos tres últimos especímenes se registraron huellas de corte.

Por otra parte, para la elaboración del Índice de Artiodáctilo (IA) se tuvieron en cuenta los restos esqueletales de Meso Rodentia (NISP=34) y Dasypodidae $(\mathrm{NISP}=51)^{10}$ en relación a los de L. guanicoe (NISP=226), cuyo valor fue de 0,72. Como $L$. guanicoe es el taxón con evidencia de utilización antrópica más representado en QS1 y el de mayor masa corporal se aplicaron algunas medidas cuantitativas adicionales. Los valores de la utilidad promedio fueron de 24,14 para todos los elementos y de 28,8 para los elementos de alta supervivencia. En tanto que el Índice CABEZA/MIEMBROS arrojó un valor de 0,16 y el Índice de Completitud Anatómica (tNME/NMI estandarizado) dio como resultado 18,4. En relación con las medidas de fragmentación para L. guanicoe, la Completitud\% dio 6,66\% y la razón NISP/NME 1,77.

\section{Discusión}

Las variables tafonómicas registradas sobre los especímenes óseos y la distribución vertical de algunas de ellas y de otros materiales, así como el contexto estratigráfico de QS1 permiten abordar el ambiente de depositación de los restos arqueológicos, la historia del conjunto faunístico y los diferentes agentes y procesos que afectaron la integridad del sitio. La evolución microambiental muestra que QS1 pasó de un cuerpo de agua que se desecó hacia la acumulación de sedimentos eólicos, con el posterior desarrollo de un paleosuelo cumúlico (Steffan et al. 2010). En estos ambientes se depositaron los materiales arqueológicos; la abrasión sedimentaria y la meteorización ratifican las interpretaciones paleoambientales. Es decir que, y aunque se depositaron escasos especímenes por debajo de los

\footnotetext{
10 Se consideran sólo 34 especímenes de los 91 de Meso Rodentia
}

ya que 57 son esmalte de dientes y 51 restos de los 325 de Dasypodidae ya que 274 son placas dérmicas. 
$100 \mathrm{~cm}$, el agua erosionó los especímenes y al mismo tiempo los protegió de las condiciones meteóricas a diferencia de lo que sucedió en los niveles superiores.

Por otra parte, en los estratos de mayor concentración de restos (80-100 cm de profundidad) y en los niveles superiores $(65-80 \mathrm{~cm})$ los menores porcentajes de especímenes abradidos así como una mayor representación de los estadios medios de meteorización sugerirían un medio en el que el agua no fue el agente responsable de la abrasión ni de protección de los restos y sí, en cambio, coincidiría con un ambiente dominado por la acumulación y erosión eólica. Incluso, se puede sugerir que los escasos especímenes en estadio 2 de abrasión, registrados entre los $65-80 \mathrm{~cm}$, fueron consecuencia de la re exposición de parte de los materiales arqueológicos. Los carnívoros parece que no actuaron en gran medida. Una vez sepultados los materiales arqueológicos fueron afectados tanto por roedores como, principalmente, por raíces y por las condiciones edáficas del paleosuelo cumúlico, que ocasionaron la obliteración de trazas anteriores (antrópicas y naturales).

Los distintos procesos tafonómicos que afectan la integridad del sitio fueron reunidos en tres grandes grupos. En el primero de ellos se incluyen los procesos que incorporan materiales faunísticos. De acuerdo con las trazas antrópicas relevadas, la representación de partes esqueletarias y la distribución vertical de los especímenes (véase Supra) se interpreta que el principal agente que incorporó restos de vertebrados grandes (guanaco, venado y ñandú) en QS1 fue el ser humano. En el caso de los mesomamiferos (armadillos y roedorores) la determinación de restos termoalterados (Grill et al. 2010; March et al. 2019) y la distribución vertical de los especímenes de armadillos, en la que las mayores frecuencias coincidieron con la de los materiales arqueológicos (Steffan et al. 2010: Figura 5), permitiría sugerir que gran parte de estos taxa ingresaron antrópicamente al sitio. En cambio, los micromamíferos, especialmente Ctenomys sp., habrían muerto naturalmente en el sitio. Esto se sustenta por la ausencia de evidencias de utilización humana, la detección durante la excavación de elementos articulados y la gran cantidad de especímenes de estos vertebrados a más de $100 \mathrm{~cm}$ de profundidad, por debajo de los niveles de mayor concentración de restos arqueológicos (Steffan et al. 2010).

En el segundo grupo se incluyen aquellos procesos que mezclaron los materiales en el sitio: aunque no deben descartarse otros agentes, los principales habrían sido las raíces y los roedores. De acuerdo con la extensión del grabado de la superficie de la mayoría de los especímenes (véase en el apartado de Análisis Tafonómico) y atendiendo al tipo de raíces (adventicias o principal, véase Strasburger 1994) se propone que la vegetación responsable de las trazas, desplazamientos y mezclas habría sido de tipo monocotiledónea (raíces adventicias), más probablemente de la familia de las gramíneas. Sin embargo, se requiere una mayor evaluación de este agente y trabajos actualíticos específicos.

El otro agente bioturbador que generó mezcla de materiales fueron los micromamíferos, particularmente Ctenomys sp. En este sentido Steffan et al. (2010: 222) mencionaron que "entre los $55 \mathrm{~cm}$ hasta los $120 \mathrm{~cm}$ de profundidad se detectaron galerías y cuevas en las plantas de excavación" y se determinó más de 40 individuos de esa especie fosorial, la mayoría de sus restos recuperados por debajo de los $100 \mathrm{~cm}$ de profundidad. También, refuerza y precisa la idea del accionar de este agente el análisis efectuado sobre la distribución vertical de los materiales (general y la de sus tamaños), siguiendo a Bocek (1986) y Durán (1991) (véase Figuras 1b y 3).

Específicamente, era de esperarse que la bimodalidad observada en la Figura $1 \mathrm{~b}$ se representara con un pico superior $(70-75 \mathrm{~cm})$ de materiales de menor tamaño con respecto al pico inferior $(80-100 \mathrm{~cm})$ de frecuencias. Como se distingue en la Figura 3, esto sucede con la distribución de los restos faunísticos (ajustándose más al modelo de Durán 1991 que al de Bocek 1986; es decir, los restos se distribuyen con un pico superior y otro inferior de materiales pequeños y uno medio de tamaño más grande).

En cambio, las frecuencias de los distintos tamaños de los artefactos líticos co-varían en el pico superior y no se comportan según lo esperado por los modelos de Bocek (1986) y Durán (1991). Por otra parte, y si bien el pico inferior $(80-100 \mathrm{~cm})$ se descompone en dos sub-picos (uno superior de litos pequeños y otro inferior de mayor tamaño) la actividad de los micro-roedores quizá no fue lo suficientemente intensa para generar una bimodalidad marcada en estos niveles. Por todo esto, el accionar de los micromamíferos mezcló materiales de distintas ocupaciones, más que nada entre los niveles $80-100 \mathrm{~cm}$ de profundidad.

Con relación a lo anterior, y articulando con los procesos que afectan la representación de los restos faunísticos debido a la destrucción y el transporte selectivo (tercer grupo), la acción de roído de los micro-roedores sobre los especímenes afectó la representación de aquellos huesos y/o porciones menos densas. De acuerdo con los porcentajes de especímenes con marcas de roedores (véase apartado Análisis Tafonómico) ese accionar fue más intenso por debajo de los $80 \mathrm{~cm}$ de profundidad, acentuándose debajo de los $100 \mathrm{~cm}$ y en coincidencia con las mayores frecuencias de restos de Ctenmoys sp.

A su vez, el desplazamiento de esos animales fosoriales fracturaron probablemente algunos especímenes óseos dificultando luego su identificación específica. Ese movimiento fue más intenso en los niveles medios (80- 
$100 \mathrm{~cm}$ ) e inferiores (debajo de los $100 \mathrm{~cm}$ ) del sitio, en contraposición con los niveles superiores $(65-80 \mathrm{~cm})$. De hecho, y aunque no de manera exclusiva como agente responsable, hay un aumento notorio de la fragmentación a medida que se desciende en los niveles estratigráficos. Es decir, en los niveles superiores los especímenes indeterminados menores a los $2 \mathrm{~cm}$ son del $23,7 \%$ y, en cambio, en los niveles medios e inferiores aumentan a $43,4 \%$ y $56,7 \%$, respectivamente.

Otras trazas vinculadas a estos procesos fueron la degradación y disolución química, más frecuente en los niveles superiores (sobre todo $70-75 \mathrm{~cm}$ ) y en coincidencia con el horizonte $2 \mathrm{~A} 2$ del paleosuelo. En cambio, una más alta cantidad de especímenes con marcas de raíces se identificaron en los niveles de mayor concentración de restos arqueológicos (más que nada entre los 95-100 cm de profundidad), en coincidencia con el horizonte $2 \mathrm{C}$ del paleosuelo. Por lo cual, (véase el párrafo anterior), la vegetación (por ej. las raíces) influyó seguramente en la intensidad de la fracturación, siendo más frecuente en aquellos restos que presentaban fisuras y grietas previas. Pero, tanto las raíces como el desarrollo pedogenético generaron la disolución y degradación química produciendo la pérdida de información zooarqueológica, sobre todo en los niveles superiores del sitio.

Asimismo, la meteorización habría afectado más severamente a los restos faunísticos de los niveles con mayor concentración de materiales arqueológicos. Aunque se registró un escaso porcentaje de especímenes con marcas de carnívoros, estos pudieron acceder secundariamente al conjunto faunístico generando la destrucción ósea así como el transporte de ciertas partes esqueletarias. Por último, no debe olvidarse tanto el transporte diferencial como el procesamiento realizado por los seres humanos.

Con relación a esta clase de procesos, los que destruyen y/o transportan partes esqueletarias, cobran importancia los estudios de densidad mineral ósea. La mayor frecuencia relativa de epífisis más densas en QS1 indicarían un sesgo en la destrucción de las partes esqueletarias mediadas por la densidad mineral ósea. Aunque nada despreciable fue el accionar antrópico fracturando huesos (véase $\%$ de fracturas en fresco en Tabla 3), la proporción de articulares enteros (Lyman 1994; Miracle 2002) sugeriría que muchos de los especímenes se fracturaron por causas naturales. Por lo cual, se puede sostener que el accionar de roedores, raíces, desarrollo pedogenético, la meteorización, los seres humanos y, quizá, los carnívoros afectaron la representación esqueletaria y fragmentaron intensamente el conjunto faunístico en QS1.

Con respecto a la utilización de la fauna, y aunque se identificó un fragmento de Mollusca (Tabla 1) que podría corresponder a un taxón marino, sólo taxones continentales presentaron evidencias claras de aprovechamiento antrópico. Al menos cinco taxa fueron aprovechados, cuatro mamíferos y un ave, y sus restos descartados en QS1. En Grill et al. (2010) y March et al. (2019) se mencionó que restos de cernidor de roedores y armadillos presentaban evidencia de termoalteración (véase más arriba sobre la distribución vertical de los restos de estos mamíferos).

De mayor porte y con evidencias más claras de explotación antrópica fueron aprovechados como recursos complementarios el ñandú y el venado. Con relación con esta gran ave, previamente no identificada (Grill et al. 2010; March et al. 2007), se registraron aquellas partes esqueletarias que representan unidades anatómicas con abundante carne (tibiotarso y fémur) y con la mayor cantidad de médula ósea (tibiotarso) (Giardina 2006). De la comparación del perfil esquelético de venados de las pampas con el GUI\% obtenido para Ovis aries (Binford 1978) se deduce que la representación anatómica en QS1 de este cérvido habría provisto bajo contenido de tejidos comestible. Asimismo, se registró el aprovechamiento de la médula ósea de este taxón (húmero) y March et al. (2019) reconocieron un especímen termoalterado.

Lama guanicoe fue el vertebrado utilizado más importante, tanto por su tamaño corporal como numéricamente $(\mathrm{NISP}=226, \mathrm{NME}=137, \mathrm{NMI}=7$ e I.A. $=0,72)$. El grado de resolución de las clases de edad permite proponer que se predó, al menos, sobre grupos familiares de este camélido. Con relación a las partes esqueletarias, se notó una marcada subrepresentación del esqueleto axial (menos del 30\% del MAU\% en comparación al esqueleto apendicular). Aunque estas diferencias podrían ser función tanto de procesos tafonómicos naturales como de decisiones antrópicas (de transporte y de consumo), la correlación estadísticamente significativa entre el MAU\% y el IS\% indicaría la presencia en QS1 de aquellas unidades anatómicas vinculadas al consumo inmediato (sensu De Nigris y Mengoni Goñalons 2005).

Ahora bien, cuando se considera sólo el esqueleto apendicular y sus distintos indicadores (las frecuencias de sus elementos, la única huella de fileteo, las proporciones de especímenes con rasgos de fractura antrópica, la relación alta y positiva entre el Índice de Medula y el MAU\% de las diáfisis, los índices NISP/ NME y Completitud\%) parece claro que se dio un aprovechamiento de aquellas partes anatómicas con abundante carne y médula (húmero y fémur) (Borrero 1990; De Nigris 2004; Mengoni Goñalons 1999; Wolverton 2002, entre otros). Sin embargo, las altas proporciones de las epífisis distales tanto de la tibia como de los metapodios (Tabla 2) no parecen estar relacionadas con el aprovechamiento de la carne y/o médula de esas unidades anatómicas.

Con respecto a esto último, Aguerre (2000) destacó que 
algunas poblaciones originarias de Santa Cruz dejaban adheridos a los cueros de L. guanicoe los huesos del pie (metapodios y falanges). Una observación personal en el desposte y cuero de Ovis aries (década de 1980, localidad de Maipú, prov. de Bs. As.) se registró que en la desarticulación de los pies se lo hacía por los articulares, dejando incluidos al cuero algunos huesos tarsianos-carpianos, los metapodios y las falanges con el objetivo de poder estaquear más eficientemente las pieles. Asimismo, en febrero de 2008 (precordillera de la prov. de San Juan) se reconoció una pata de guanaco descartada que incluía la epífisis distal de la tibia fracturada, tarsianos, metatarso y falanges (Figura 4). En definitiva, la abundante presencia de epífisis distales de tibia y metapodios en QS1 podría relacionarse al trabajo de los cueros y/o como acompañante de los mismos y/o descarte de esa región anatómica.

Por otra parte, algunas partes esqueletarias subrepresentadas de guanaco (como por ejemplo vértebras y costillas) podrían haber quedado incluidas en categorías taxonómicas amplias (Mammalia grande y/o Artiodactyla). Sin embargo, costillas, vértebras y huesos largos siguen proporciones similares en ambas categorías taxonómicas (Lama sp. vs. Mammalia grande-Artiodactyla). Por lo cual, quizá vértebras $y$, sobre todo, costillas no fueron descartadas en QS1 tan frecuentemente como los huesos largos.

Ahora bien, tanto las vértebras como los huesos largos dentro de las categorías taxonómicas amplias podrían haber correspondido a distintas unidades anatómicas y por ende con diferentes rindes. En este sentido se aplicó a una muestra pequeña la propuesta metodológica sobre identificación de elementos y taxa a partir de rasgos cuali-cuantitativos diafisiarios. La tendencia para QS1 corrobora lo antedicho ya que se reconocieron cuatro especímenes pertenecientes al esqueleto apendicular superior (húmero y fémur) y uno al medio (radio-cúbito y tibia) o inferior (metapodios) de un mamífero de tamaño similar a L. guanicoe.

La correlación alta, negativa y significativa estadísticamente entre el MAU\% y IS\% sugeriría el transporte diferencial e ingreso de aquellas partes anatómicas de guanaco poco propensas al secado (De Nigris y Mengoni Goñalons 2005). Sumando a lo anterior, y según Muñoz (2006), el valor muy bajo $(18,4)$ de la Completitud Anatómica (tNME/NMI estandarizado) señalaría el alto procesamiento de este camelido y/o su transporte diferencial. Pero, tanto el Índice CABEZA/MIEMBROS como los valores de la Utilidad Promedio indican claramente el transporte diferencial de este taxón. Es más, la Utilidad Promedio para los elementos de alta supervivencia (28,8 en QS1 vs. guanaco entero 20,35) corrobora no solo el transporte diferencial; sino que además el valor para el sitio es casi de una vez y media más alto que para una carcasa entera $y$, por lo tanto, podría señalar el ingreso de unidades
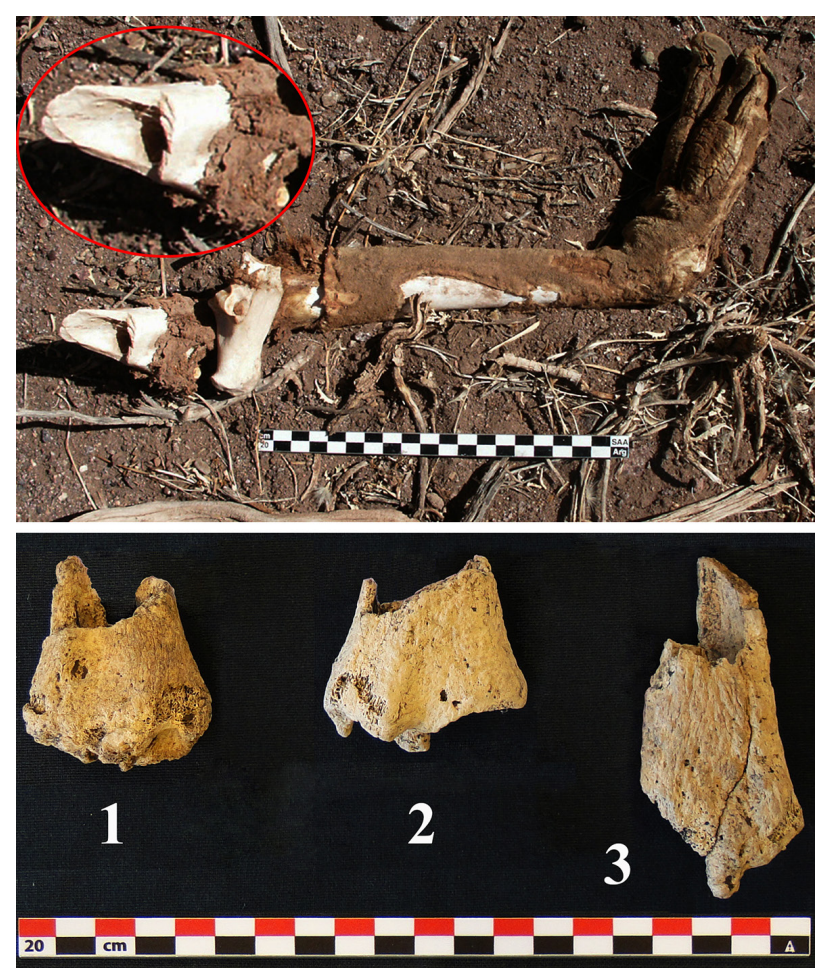

Figura 4. Arriba pata de guanaco (con detalle de tibia distal fracturada); abajo tres tibias distales fracturas de QS. Referencias: 1- Pieza FCS.QS1.1020; 2- Pieza FCS.QS1.380; 3- Pieza FCS.QS1.633

Figure 4. Top of guanaco paw (with detail of fractured distal tibia); down three tibial distal fractures of QS. References: 1Piece FCS.QS1.1020; 2- Part FCS.QS1.380; 3-Piece FCS.QS1.633

anatómicas con valores de utilidad medios y altos.

QS1 fue caracterizado, en un trabajo previo (Bonomo 2004:479), como un campamento base, con una sucesión de ocupaciones domésticas, ya que se destacó el desarrollo de actividades diversas vinculadas a las distintas "tareas de producción artefactual, numerosos pigmentos minerales y de alfarería". Con relación a los artefactos líticos en QS1 se registraron 55 instrumentos de distintos grupos tecnológicos y Bonomo (2004) destacó que por la presencia de varias puntas de proyectil habría sido un sitio de actividades múltiples, orientado principalmente a la caza de guanacos y venados con arco y flecha.

Bonomo (2004, 2005), en su modelo de ocupación diferencial de los microambientes del litoral marítimo del área Interserrana (Bonomo2004: Figura IX.1), articuló en sentido transversal los contextos arqueológicos de los médanos con los de la llanura adyacente. Destacó que cada microambiente en particular, además de que existieran disponibles distintos taxa, estaría vinculado con una tendencia funcional determinada. Es decir, actividades específicas en campamentos temporarios en la playa y médanos móviles y actividades múltiples en campamentos residenciales en los médanos semi-fijos/ 
Tabla 4. Conjuntos faunísticos de las llanuras adyacentes a la costa e interiores. Referencias: IA=Índice de Artiodactilos; UPL.g.=Utilidad promedio de los elementos de alta supervivencia de L. guanicoe.

Table 4. Faunal assemblages of the plains adjacent to the coast and inland. References: IA =Artiodactyly Index; UPL.g. = Average utility of the elements of high survival of L. guanicoe.

\begin{tabular}{|l|c|c|c|c|l|}
\hline \multicolumn{1}{|c|}{ Sitio } & IA $^{1}$ & UPL.g. & Cronologia & Funcionalidad & \multicolumn{1}{c|}{ Referencia } \\
\hline Empalme Querandies 1 & 0,88 & 24,38 & $3095-2052$ & Actividades múltiples & Álvarez (2012) \\
\hline Nutria Mansa 1 & 0,99 & 22,2 & $3080-2705$ & Actividades múltiples & Bonomo $(2004,2005)$ \\
\hline Tres Reyes 1, Componente Superior & 0,95 & 24,35 & $2280-1845$ & Actividades múltiples? & Salemme y Madrid (2007) \\
\hline Cortaderas & 0,9 & 20,75 & 2270 & Actividades múltiples & Massigoge (2009) \\
\hline La Toma, Componente Superior & 0,61 & 32,1 & 995 & Actividades múltiples & Álvarez (2012) \\
\hline Quequén Salado 1 & 0,72 & 28,8 & $960-790^{2}$ & Actividades múltiples & Este trabajo \\
\hline Claromecó 1 & 0,62 & 28,04 & 840 & Actividades múltiples & Leon 2014a \\
\hline
\end{tabular}

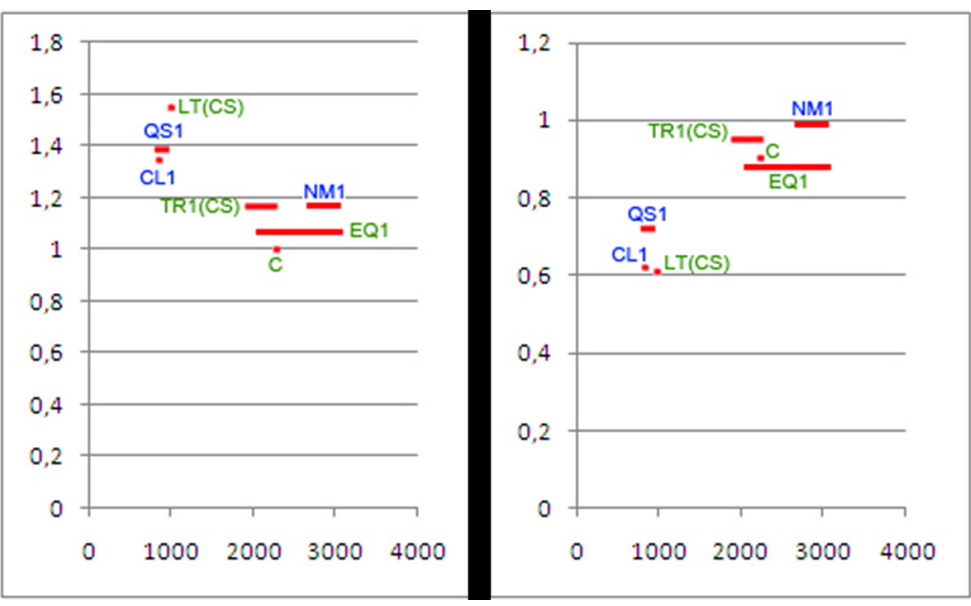

completo y/o de las partes anatómicas de mayor rinde de, casi exclusivamente, fauna continental (Bonomo et al. 2008; Leon 2014a).

Para el Holoceno tardío la evidencia zooarqueológica en estratigrafía para el litoral marítimo del área Interserrana proviene exclusivamente de sitios de actividades múltiples localizados detrás de la cadena actual de médanos. La composición faunística de QS1 se asemeja a la de Claromeco 1 (ca. 800 AP y a $3 \mathrm{~km}$ ) y Nutria Mansa I (ca. 3000-2700 AP y a 3,5 km del litoral). En estos tres sitios los

Figura 5. Utilidad promedio de los elementos de alta supervivencia de L. guanicoe observada/esperada (izquierda) e Índice de Artiodáctilo (derecha). Referencias: Sitios del litoral marítimo (en azul); NM1=Nutria Mansa 1; QS1=Quequén Salado 1; CL1=Claromecó 1. Sitio del interior (en verde); EQ1=Empalme Querandíes 1; C=Cortaderas; TR1(CS)=Tres Reyes 1, componente superior; $\mathrm{LT}(\mathrm{CS})=\mathrm{La}$ Toma, componente superior. Nota: en el eje $\mathrm{X}$ la cronología.

Figure 5. Average utility of the elements of high survival of L. guanicoe observed / expected (left) and Artiodactyl Index (right). References: Maritime coastal sites (in blue); NM1 = Nutria Mansa1; QS1 = Quequén Salado 1; CL1 = Claromecó 1. Interior site (in green); $E Q 1=$ Empalme Querandies 1; $C=$ Cortaderas; $T R 1(C S)=$ Tres Reues 1, upper component; $L T(C S)=$ La Toma, upper component. Note: on the $X$ axis the chronology.

fijo y en las Ilanuras adyacentes, sobre todo en este último espacio.

Con relación a la utilización de la fauna se propuso recientemente (Bonomo et al. 2013; Leon 2014a), y de manera complementaria al modelo general de Bonomo (2004), que en las ocupaciones de la cadena de médanos móviles se habría dado un consumo incidental de la fauna marina y continental, y también un desposte inicial de estos últimos taxones (véase sitio Alfar de 5700 años AP, Bonomo y Leon 2010; Leon 2014a). En cambio, en los campamentos base de los médanos semi-fijos/fijo y en las llanuras adyacentes se habría dado el consumo e ingreso especímenes de vertebrados continentales representan el $100 \%, 100 \%$ y $99,97 \%$, respectivamente. En todos ellos, la principal presa explotada por los cazadoresrecolectores fue el guanaco (Bonomo 2004; Bonomo et al. 2008; Leon 2014a).

Para introducir en la discusión del área Interserrana de la región pampeana durante el Holoceno tardío, por un lado, la relación costa-interior abordada desde la zooarqueología y, por otro lado, las estrategias de subsistencias para ese momento temporal se consideraron la utilidad promedio de los elementos de alta supervivencia de L. guanicoe y el Índice de Artiodáctilo de seis sitios, además de QS1, con funcionalidad definida y con registro faunístico en estratigrafía (Tabla 4). Como primera observación se destaca que tanto los valores de la utilidad promedio así como el IA para los sitios de las llanuras adyacentes a la cadena de médanos coinciden con los contextos arqueológicos contemporáneos de las llanuras interiores (Figura 5). Estas medidas serían otra línea de evidencia, zooarqueológicas, que corrobora la relación costa-interior propuesta por Bonomo (2004).

Por otra parte, los valores del IA son cercanos a uno en los contextos del Holoceno tardío inicial (NM1, EQ1, C, TR1CS), es decir que L. guanicoe estuvo altamente jerarquizado por los indígenas prehispánicos. Respecto a las utilidades promedio, que son cercanas a uno (observada/esperada), indicarían que las carcasas de $L$. guanicoe habrían ingresado prácticamente enteras a estos sitios de actividades múltiples (NM1, EQ1, C, TR1CS). 
En cambio, en los sitios del Holoceno tardío final (LTCS, QS1 y CL1), se dio un rápido descenso del IA y un rápido incremento de la utilidad promedio. Esto evidencia un ingreso diferencial de las carcasas de L. guanicoe a los sitios y una disminución relativa de este artiodáctilo en la dieta de las poblaciones prehispánicas (Tabla 4, Figura 5).

De acuerdo con lo anterior, el modelo de Martínez y Gutiérrez (2004) acerca de la continuidad de una economía especializada de los grupos prehispánicos en la caza del guanaco desde el Holoceno medio hasta el Holoceno tardío final en el área Interserrana se mantiene, pero se ha complejizado. Como se mencionó en los párrafos anteriores, y como diversos autores han planteado recientemente (Álvarez 2014; Álvarez y Salemme 2015; Frontini 2013; Martínez y Gutiérrez 2004; Massigoge 2007; Massigoge et al. 2018; Messineo 2011; Messineo y Scheifler 2016), continúa la centralidad del guanaco en las dietas prehispánicas hasta momentos previos al contacto, pero hacia el 1000 AP se corrobora una disminución relativa de este artiodáctilo quizá como producto de su ingreso diferencial (LTCS; QS1 y CL1).

Entonces, en el área Interserrana la especialización en la caza de $L$. guanicoe se mantuvo hasta momentos previos al contacto, pero el establecimiento de las condiciones climáticas actuales (a partir de los ca. 1000 años AP) generó algunas particularidades sobre las estrategias implementadas por los cazadores-recolectores. Si las condiciones paleoclimáticas fueron similares a las actuales entonces es oportuno destacar que, de acuerdo con el modelo potencial de distribución de L. guanicoe propuesto por Politis et al. (2011), sólo en el sudoeste (sitio La Toma; véase Álvarez y Salemme 2015) y en la cadena de médanos, o próxima a ella (Quequén Salado 1 y Claromecó 1), se encontrarían aún poblaciones de este artiodáctilo. Es por eso que en el área Interserrana, la cadena de médanos podría haber actuado como una cuña de condiciones áridas favoreciendo el ingreso y/o permanencia de ese camélido (Contreras y Reig 1965; Pardiñas et al. 2004; Politis y Pedrotta 2006:304; Politis et al. 2011: Figura 2), tal vez de poblaciones relictuales.

En síntesis, los materiales descartados por los indígenas prehispánicos en el sitio Quequén Salado 1 fueron afectados por diversos agentes y procesos. Entre los más importantes, por las mezclas que ocasionaron y por como afectaron la representación esqueletal, se determinaron a los micro-roedores y todos los relacionados con el desarrollo del paleosuelo cumúlico (raíces y procesos pedogenéticos). Aun así, se pudo establecer la utilización antrópica como recursos complementarios de venado de las pampas, ñandú, armadillos y, probablemente, mesoroedores. Diversas herramientas analíticas, además de las ya clásicas, permitieron corroborar la preeminencia del guanaco en la dieta prehispánica y su transporte diferencial. Aunque se sugirió que parte de los huesos largos ingresaron como parte de los cueros, los indígenas se focalizaron en aquellas unidades anatómicas vinculadas con el consumo inmediato y con mayor cantidad de carne y medula ósea.

Quequén Salado 1 relaciona arqueológicamente la costa marítima con el interior del área Interserrana. A su vez, aporta a la discusión de las estrategias de subsistencia prehispánicas del Holoceno tardío final. En ese sentido se planteó que la menor participación del guanaco en la dieta prehispánica se debió a una menor completitud anatómica como resultado del transporte diferencial. Esto se habría debido a un mayor tiempo de búsqueda de un recurso que se estaba retrayendo, localizable con mayor frecuencia en el sudoeste y en la cadena de médanos.

Santiago del Estero, 23 de mayo 2019

\section{Agradecimientos}

Se quiere agradecer especialmente al Dr. Gustavo Politis y la Lic. Patricia Madrid, directores argentinos del proyecto de cooperación internacional SETCIP-ECOSsud (A98H02). A los doctores Mariano Bonomo y Gustavo Martínez, director y co-director de tesis doctoral respectivamente, quienes leyeron y realizaron sugerencias sumamente importantes a una versión anterior de esta manuscrito, cuando aún era un capítulo de tesis doctoral. Al doctor Gustavo Gómez por haber cedido sus planillas de análisis del material de meso y micro mamíferos. Al Lic. Roberto "Charly" Peretti, encargado de las colecciones del INCUAPA (CONICET-UNICEN). A los dos revisores de este trabajo por sus importantes sugerencias. El único responsable del contenido de este trabajo es quien suscribe este artículo.

\section{Bibliografía}

Aguerre, A.M. (2000) Las vidas de Pati en la toldería Tehuelche del Río Pinturas y el después. Facultad de Filosofía y Letras, Universidad de Buenos Aires.

Álvarez, M.C. (2012) Análisis Zooarqueológicos en el sudeste de la región pampeana. Patrones de subsistencia durante el Holoceno tardío. Tesis de Doctorado inédita, Facultad de Ciencias Sociales, Universidad Nacional del Centro de la Provincia de Buenos Aires, Olavarría. http:// www.ridaa.unicen.edu.ar/xmlui/handle/123456789/1684

Álvarez, M.C. (2014) Subsistence patterns during the Holocene in the Interserrana área (Pampean region, Argentina): Evaluating intensificationin resource exploitation. Journal of Anthropological Archaeology 34: 54-65

Álvarez; M.C., Salemme, M. (2015) Tendencias en la subsistencia en el Holoceno tardío enla región pampeana, Argentina: el caso del sitio La Toma (partido de Coronel Pringles, provincia de Buenos Aires). 
Aschero, C. (1975) Ensayo para una clasificación morfológica de artefactos líticos. Informe CONICET, ms.

Behrensmeyer, A. (1978) Taphonomic and ecologic information from bone weathering. Paleobiology 4:150162

Binford, L.R. (1978) Nunamiut ethnoarchaeology. Academic Press, New York.

Binford, L.R. (1981) Bones: ancient men and modern myths. Academic Press, New York.

Bocek, B. (1986) Rodent ecology and burrowing behavior: predicted effects on archaeological site formation. American Antiquity 51(3):589-603.

Bonomo, M. (2004) Ocupaciones humanas en el litoral marítimo pampeano: un enfoque arqueológico por sociedades cazadoras-recolectoras prehispánicas. Tesis Doctoral inédita. Facultad de Ciencias Naturales y Museo, Universidad Nacional de La Plata. La Plata.http://sedici.unlp. edu.ar/handle/10915/4287

Bonomo, M. (2011) The Use of the Space in the Pampean Atlantic Coast and the Adjacent Plains (Argentina, South America): A Comparative View. En Trekking the Shore. Changing Coastlines and Antiquity of Coastal Settlement, editado por N.F. Bicho, J.A. Haws y L.G. Davis, pp. 333353. Springer.

Bonomo, M., Leon, D.C. (2010) Un contexto arqueológico en posición estratigráfica en los médanos litorales. El sitio Alfar (Pdo. de General Pueyrredón, Pcia. De Buenos Aires). En Mamul Mapü: pasado y presente desde la arqueología pampeana, editado por M. Berón, L. Luna, M. Bonomo, C. Montalvo, C. Aranda y M. Carrera Aizpitarte, Tomo II, pp. 29-45. Libros del Espinillo, Ayacucho.

Bonomo, M., Scabuzzo, C., Leon, D.C. (2013) Cronología y dieta en la costa atlántica pampeana, Argentina. Intersecciones en Antropología 14: 123-136.

Bonomo M., Leon, D.C,. Turnes, L, Apolinaire, E. (2008) Nuevas investigaciones sobre la ocupación prehispánica de la costa pampeana en el Holoceno tardío: el sitio arqueológico Claromecó 1 (partido de Tres Arroyos, provincia de Buenos Aires). Intersecciones en Antropología 9:25-41.

Borrero, L.A. (1989) Sites in action: the meaning of guanaco bones in Fuegian archaeological sites. Archaeozoologia 3(1-2):9-24.

Borrero, L.A. (1990) Fuego-Patagonian bone assemblages and the problem of comunal guanaco hunting. En Hunters of the Recent Past, editado por L. B. Davis y B. O. K. Reeves, pp. 373-399. Unwin Hyman, Londres.

Broughton, J.M. (1994) Late Holocene resource intensification in the Sacramento Valley, California: The vertebrate evidence. Journal of Archaeological Science 21(4):501-514.

Buikstra, J., Swegle, M. (1989) Bone modification due to burning: experimental evidence. En Bone modification, editado por R. Bonnichsen y M. Sorg, pp. 247-258. Center for theStudy of the First Americans, Universidad de Maine. Orono.

De Nigris, M.E. (2004) El consumo en grupos cazadores re-colectores. Un ejemplo zooarqueológico de Patagonia Meridional. Sociedad Argentina de Antropología. (Tesis de Doctorado).

De Nigris, M.E., Mengoni Goñalons, G.L. (2005) The guanaco as a source of meat and fat in the Southern Andes. En The Zooarchaeology of Fats, Oils, Milk and Dairying, editado por Mulville J., Outram, A., pp. 160-166.Oxbow Books, Durham.

Durán, V. (1991) Estudios de perturbación por roedores del género Ctenomys en un sitio arqueológico experimental. Revista de Estudios Regionales 7:7-31.

Fisher, J.W. (1995) Bone Surface Modifications in Zooarchaeology. Journal of Archaeological Method and Theory 2(1):7-68.

Frontini, R. (2013) Aprovechamiento faunístico en entornos acuáticos del sudoestebonaerense durante el Holoceno (6.900-700 años AP). Relaciones de la SociedadArgentina de Antropología. XXXVIII(2): 493-519.

Gómez, G., Prado, J.L., Alberdi, M.T. (2005) Diagenetical modifications in small Holocene bones from Quequén Salado 1 (Argentina). Ms.

Grayson, D.K. (1984) Quantitative Zooarchaeology. Academic Press, Orlando.

Grill, S., March, R., C. Rodriguez Loredo (2010) Sitio arqueológico QS1 (provincia de Buenos Aires, Argentina): evidencias palinológicas de fluctuaciones paleoclimáticas durante los últimos 1000 años AP. Comechingonia: Revista de Arqueología 13:59-76.

Gutiérrez, M.A. (2004) Análisis tafonómicos en el Área Interserrana (provincia de Buenos Aires).Tesis Doctoral inédita, Facultad de Ciencias Naturales y Museo, Universidad Nacional deLa Plata.http://sedici.unlp.edu.ar/ handle/10915/4574

Gutiérrez, M.A., Kaufmann, C.A. (2007) Criteria for the Identification of Formation Processes in Guanaco (Lama guanicoe). Bone Assemblages in Fluvial-Lacustrine Environments. Journal of Taphonomy 5(4):151-176.

Gutiérrez, M.A., Martínez, G. (2008) Trends in the faunal human exploitation during the Late Pleistocene and Early 
Holocene in the Pampean Region (Argentina). Quaternary International 191:53-68.

Inda, H., del Puerto, L., Castiñeira, C., Capdepont, I., GarcíaRodríguez, F. (2006) Aprovechamiento prehistórico de recursos costeros en el litoral atlántico uruguayo. En Bases para la conservación y el manejo de la costa uruguaya, editado por Menafra, R., Rodríguez-Gallego, L., Scarabino, F. Conde, D., pp. 661-667. SUCN, Montevideo.

Johnson, E. (1985) Current developments in bone technology. En Advances in Archaeological Method and Theory, editado por Schiffer, M. B., Vol. 8, pp. 157-235. Academic Press, New York.

Kaufmann, C.A. (2009) Estructura de edad y sexo en guanaco. Estudios actualísticos en Pampa y Patagonia. Colección de Tesis Doctorales, Sociedad Argentina de Antropología. Buenos Aires.

Leon, D.C. (2010) Identificación taxonómica y anatómica de muestras arqueofaunísticas a partir de fragmentos diafisiarios de huesos largos. En Zooarqueología a principios del siglo XXI: Aportes teóricos, metodológicos y casos de estudio, editado por Gutiérrez, M., De Nigris, M., Fernández, P., Giardina, M., Gil, A., Izeta, A., Neme, G., Yacobaccio, H., pp. 145-155. Libros del Espinillo, Ayacucho.

Leon, D.C. (2014a) Zooarqueología de cazadores recolectores del litoral pampeano: un enfoque multidimensional. Tesis Doctoral inédita. Facultad de Ciencias Sociales, Universidad Nacional del Centro de la Provincia de Buenos Aires. Olavarría. http://www.ridaa.unicen.edu.ar/xmlui/ handle/123456789/1893

Leon, D.C. (2014b) Diferenciación de especies animales silvestres a partir de rasgoscualitativos internos de la diáfisis. Ciencias Morfológicas 16(2): 8-21.

Lima, T.A. (1999-2000) En busca dos frutos do Mar: os pescadores-colectores do litoral centro meridional brasileiro. Revista USP 44(2):270-327.

Lyman, R.L. (1994) Vertebrate Taphonomy.Cambridge Manuals in Archaeology. Cambridge University Press, Cambridge.

Lyman, R.L. (2008) Quantitative paleozoology. Cambridge University Press, Cambridge.

Madrid, P., Politis, G., March, R., Bonomo, M. (2002) Arqueología microrregional en el Sudeste de la Región Pampeana Argentina: El curso del río Quequén Salado. Relaciones de la Sociedad Argentina de Antropología 27:327-355.

March, R.J., Rodríguez Loredo, C., Madrid, P., Bonomo, M., Politis, G., Joly, D., Laporte, L. Grill, S. (2007) Évolutionet adaptation humaine autour de la région des plaines et lacs du fleuve Quequén Salado. Pcia.de Buenos Aires
(Argentine): premiers pas d'unearchéologie régionale programmé: la prospection. BAR International Series 1524. Acts of the XIVth UISPP Congress, University of Liège, Belgium. Section17: Préhistoire de I'Amérique, editado por la Secrétariatdu Congrès. British Archaeological Reports, Oxford: 211-231.

March R. J., Rodríguez Loredo, C., Joly, D., Laporte, L., Madrid, P., Politis, G., Bonomo M. (2019) Premier pas d'une archéologierégionale programmée dans la région duQuequén Salado: Les fouilles du siteQuequén Salado 1 (Argentina). Journal de la Société des Américanistes, en prensa.

Marean, C.W. (1991) Measuring the post-depositional destruction of bone in archaeological assemblages. Journal of Archaeological Science 18(6):677-694.

Martínez, G., Gutiérrez, M.A. (2004) Tendencias en la explotación humana de la fauna durante el Pleistoceno final y Holoceno en la Región Pampeana (Argentina). En Zooarchaeology of South America, editado por Mengoni Goñalons, G., pp. 81-98. BAR International Series 1298, Oxford.

Massigoge, A. (2007) Procesos de formación del registro arqueológico en el sitio Cortaderas (partido de San Cayetano, provincia de Buenos Aires). Intersecciones en Antropología 8:197-214.

Massigoge, A. (2009) Arqueología de los cazadoresrecolectoresdel Sudeste de la región pampeana: una perspectiva tafonómica. Tesis Doctoral inédita, Facultad de Ciencias Naturales y Museo, Universidad Nacional de La Plata, La Plata. http://sedici.unlp.edu.ar/handle/10915/22949

Massigoge, A., Rodríguez, M.N., Rafuse, D.J., Torino, R.F., Favier Dubois, C, Steffan, P.G (2018) Investigaciones arqueológicas en el sitio Las Brusquillas 3 (Holoceno tardío, región Pampeana, Argentina). Arqueología 24(1): 47-171.

Mengoni Goñalons, G.L. (1999) Cazadores de guanacos de la estepa patagónica. Sociedad Argentina de Antropología, Colección Tesis Doctorales. Buenos Aires.

Messineo, P.G. (2011) Investigaciones arqueológicas en la cuenca superior del ArroyoTapalqué. Un modelo de ocupación humana para el centro de la subregión PampaHúmeda durante el Holoceno tardío. Intersecciones en Antropología 12: 275-291.

Messineo, P.G., Scheifler, N.A. (2016) Investigaciones arqueológicas de cazadores-recolectoresen el sitio Laguna Cabeza de Buey 2(centro de los pastizales pampeanos, Buenos Aires).Cincuenta años después de las Industrias Culturales definidas por Bórmida. Intersecciones en Antropología 17: 213-226.

Miotti, L., Salemme, M. (1999) Biodiversity, taxonomic richness and specialist-generalist during Late Pleistocene/ 
Early Holocene times in Pampa and Patagonia (Argentina, Southern South America). Quaternary International 53/54:53-68.

Miracle, P. (2002) Mesolithic meals from Mesolithic middens. En Consuming passions and patterns of consumption, editado por Miracle, P., Milner, N. pp. 65-88. Cambridge.

Munro, N.D. (2009) Epipaleolithic Subsistence Intensificationin the Southern Levant: The Faunal Evidence. En The Evolution of Hominin Diets.Integrating Approaches to the Study of Palaeolithic Subsistence, editado por Hublin, J.J., Richards, M.P. Springer

Muñoz, A.S. (2004) Mammal exploitation in the insular environinents of southern South America. Zooarchaeology of South America: 123-137.

Muñoz, A.S. (2006) La explotación de pinnípedos en el sitio arqueológico Punta María 2, Isla Grande de Tierra del Fuego. En Contra viento y marea. Arqueología de Patagonia, compilado por Civalero, M.T., Fernández, P.M., Guráieb, G., pp. 489-496. Sociedad Argentina de Antropología e Instituto Nacional de Antropología y Pensamiento Latinoamericano, Buenos Aires.

Nagaoka, L. (2006) Prehistoric seal carcass exploitation at the Shag Mouth site, New Zealand.Journal of Archaeological Science 33(10):1474-1481.

Nilssen, P. (2000) An actualistic butchery study in South Africa and its implications for reconstructing hominid strategies of carcass acquisition and butchery in the upper Pleistocene and Plio-Pleistocene. Tesis Doctoral inédita, Universidad de Cape Town. Sudáfrica.

Orquera, L., Gómez Otero, J. (2007) Los cazadoresrecolectores de las costas de pampa, patagonia y Tierra del Fuego. Relaciones de la Sociedad Argentina de Antropología XXXII: 75-99.

Politis, G. (1984) Arqueología del Area Interserrana Bonaerense. Tesis Doctoral inédita, Facultad de Ciencias Naturales y Museo, UNLP, La Plata.

Politis, G., Pedrotta, V. (2006) Recursos faunísticos y estrategias de subsistencia en el este de la región pampeana durante el Holoceno tardío: el caso del guanaco (Lama guanicoe). Relaciones de la Sociedad Argentina de Antropología XXXI: 301-336.

Politis, G., Salemme, M. (1990) Pre-Hispanic mammal explotation and hunting strategies in the Eastern Pampas Subregion of Argentina. En Hunters of the Recent Past, editado por Davis, L. B., Reeves, B. pp. 352-372. Unwin Hyman, London.

Politis, G., Prates, L.., Merino, M.L., Tognelli, M.F. (2011)
Distribution parameters of guanaco (Lama guanicoe), pampas deer (Ozotoceros bezoarticus) and marsh deer (Blastocerus dichotomus) in Central Argentina: Archaeological and paleoenvironmental implications. Journal of Archaeological Science 38:1405-1416.

Quintana, C.A., Mazzanti, D. (2001) Selección y aprovechamiento de recursos faunísticos. En Cueva Tixi: Cazadores y Recolectores de las Sierras de Tandilia Oriental. Geología, Paleontología y Zooarqueología, editado por Mazzanti, D.L., Quintana, C.A. pp. 181-209. Laboratorio de Arqueología, (UNMP), Publicación Especial 1, Mar del Plata.

Rawlings, T.A. (2006) Faunal analysis and meat procurement: Reconstructing the sexual division of labor at Shields Pueblo, Colorado. Tesis Doctoral inédita, Universidad de Simon Fraser, Canadá.

Salemme, M., Madrid, P. (2007) The archaefaunas from Laguna Tres Reyes 1 site: taxonomic richness andabundance during the beginning of the Late Holocene in the SouthEast Pampean Region(Argentina). En Taphonomy and Zooarchaeology in Argentina, editado por Gutiérrez, M. A., Miotti, L., Barrientos, G., Mengoni Goñalons, G., Salemme, M. pp. 121-142.BAR International Series 1601. Archaeopress, Oxford

Shipman, P. (1981) Life history of a fossil. Harvard University Press, Cambridge.

Steffan, P., Madrid, P., Gómez, G., L. Mormeneo (2010) Evaluación de la información paleoambiental y de la dinámica de ocupación humana en el curso inferior del rio Quequén Salado durante el Holoceno tardío final. En Mamül Mapu: Pasado y Presente desde la Arqueología Pampeana, editado por Berón, M., Luna, L., Bonomo, M., Montalvo, C. Aranda, C., Carrera Aizpitarte, M. Tomo II,pp. 159-172. Libros del Espinillo, Ayacucho.

Stiner, M.C (1991) Humans predators and prey mortality: westview special studies in archaeological research. Westview Press: Boulder, CO.

Strasburger, E. (1994) Tratado de Botánica. $8^{a}$ ed. castellana. Ediciones Omega S.A.

Wolverton, S. (2002) NISP: MNE and \%whole in analysis of prehistoric carcass exploitation. North American archaeologist 23(2):58-100.

Ugan, A. (2005) Does size matter? Body size, mass collecting, and their implications for understanding prehistoric foraging behavior. American Antiquity 70: 75-90.

Yepes, J. (1928) Los Edentata argentino. Revista de la Universidad de Buenos Aires, 2da.serie, sección V (1): 461-515. 